\title{
ANÁLISIS CIENTÍFICO-JURÍDICO COMPARATIVO DE LA POLÍTICA LINGÜÍSTICA EN RELACIÓN CON LAS MINORÍAS NACIONALES
}

\section{SCIENTIFIC-COMPARATIVE LEGAL ANALYSIS OF LANGUAGE POLICY IN RELATION TO NATIONAL MINORITIES}

Iliana VALIULLINA ${ }^{1}$

Resumen: Este artículo discute la política lingüística en relación con las minorías nacionales en países como Polonia, Gran Bretaña, Francia, Italia, Alemania, Austria, Bélgica y Hungría. La elección de estos países está determinada por la política linguíistica multidireccional durante sus etapas. Se presta especial atención a los actos jurídicos nacionales, así como a los actos celebrados entre países. Además, el artículo analiza en detalle los principales factores que influyeron en la política lingüística, como los levantamientos, el bajo nivel de educación y otros.

Abstract: This article discusses language policy in relation to national minorities in countries such as Poland, Great Britain, France, Italy, Germany, Austria, Belgium, and Hungary. The choice of these countries is determined by the multidirectional language policy during its stages. Special attention is paid to domestic legal acts, as well as acts concluded between countries. In addition, the article analyzes in detail the main factors that influenced language policy, such as uprisings, low level of education, and others.

Palabras clave: Política lingüística, minorías nacionales, lenguas regionales, lenguas nativas, lenguas minoritarias, tratados de paz.

Keywords: language policy, national minorities, regional languages, native languages, minority languages, peace treaties.

\section{Introduction}

El estudio de las cuestiones de política lingüística ha Estado en el centro de atención de los científicos durante más de un siglo. V. M. Alpatov cree que «el proceso de cambio de idioma nunca es completamente voluntario. Siempre como la transición del monolingüismo al bilingüismo, la transición posterior del bilingüismo al monolingüismo en un idioma previamente extranjero es forzada de alguna manera ${ }^{2} \gg$. Está claro que no siempre la presión es puramente administrativa, también puede haber coacción económica, política y cultural. Obviamente, el paso de absolutamente todas las etapas no

\footnotetext{
${ }^{1}$ Estudiante de doctorado en el Departamento de Derecho Público Internacional y Derecho Europeo de la Universidad de Derecho Estatal de los Urales, elyana.valiulina@gmail.com

${ }^{2}$ ALPATOV V. M. 150 iazykov i politika: 1917-2000. - M., 2000.
} 
es absolutamente necesario, y cada uno de los procesos descritos anteriormente puede durar siglos ${ }^{3}$.

\section{Primer período}

En la evolución de la política lingüística se destacan varias etapas. Según la mayoría de los autores, el comienzo de la política lingüística en relación con las minorías nacionales se remonta a la conclusión de los tratados de paz que pusieron fin a la primera guerra mundial. Sin embargo, N. A. Kadyirova cree que este fenómeno ocurrió mucho antes, a saber, en el siglo 16 y destaca los siguientes motivos: la consolidación de los reinos nacionales; la invención de una imprenta que permitió la distribución de material escrito en varios idiomas minoritarios; la reforma (por ejemplo, católicos y protestantes, estaban llenos de deseo de traducir las Escrituras a los idiomas locales y utilizarlas en la liturgia y la religión, lo que también ayudó a fortalecer las posiciones de las minorías lingüísticas).La situación lingüística de este período de tiempo se considera «tripartita». Por un lado, el latín fue el único vector de la cultura y el idioma de las actividades religiosas y diplomáticas, las lenguas nacionales «fuertes» se utilizaron como una herramienta para fortalecer los reinos nacionales recién formados. Por otro lado, el resto de lenguas no reconocidas por los Estados, pero utilizadas en la vida social o religiosa de la población ${ }^{4}$.

En el campo de la política lingüística de este tiempo, se destacan dos áreas opuestas:

1. La primera dirección insistió en obligar a un determinado idioma nacional a convertirse en oficial y desplazar al resto. Por ejemplo, en la Ley de la Unión de Inglaterra y Gales de 1536, el inglés fue proclamado el único idioma de los tribunales de Gales, y las personas que usaban el idioma galés no podían ocupar cargos públicos ${ }^{5}$. Otro documento, el Decreto de Villers - Cotterets de $1539^{6}$, en los artículos 110 y 111 , proclama el uso del francés en todos los actos jurídicos de Francia para evitar la confusión lingüística (ambigüedad, incertidumbre). Este decreto fue aprobado para poner fin al uso del latín en los documentos oficiales e influir en el uso de otros idiomas y dialectos utilizados en muchas regiones de Francia. Todos los documentos posteriores, incluido el Decreto de Roussillon de 1563 (artículo 35) ${ }^{7}$, contenían disposiciones que obligaban al uso del francés.

\footnotetext{
${ }^{3}$ PSHEGUSOVA G.S., IVANOVA D.N. Language policy in multicultural region: retrospective analysis// Humanities of the South of Russia. - P.67.

${ }^{4}$ KADYIROVA, N.A. Evolyutsiya protsessov po zaschite prav lingvisticheskih menshinstv v Evrope.[Elektronnyiy resurs]. Rezhim dostupa: http://sci-article.ru/stat.php?i=1454333848 (data obrascheniya: 16.11.2018).

${ }^{5}$ The Act of $1536 . \quad$ [Electronic resource]. Access mode:http://www.bbc.co.uk/wales/history/sites/themes/periods/tudors_04.shtml (date accessed: 16.11.2018)

${ }^{6}$ The Ordinance of Villers-Cotterêts. [Electronic resource]. Access mode: https://ipfs.io/ipfs/QmXoypizjW3WknFiJnKLwHCnL72vedxjQkDDP1mXWo6uco/wiki/Ordinance_of_ Villers-Cotterêts.html (date accessed: 16.11.2018).

${ }^{7}$ The Ordonnance de 1563, dite de Roussillon. [Electronic resource]. Access mode: https://gallica.bnf.fr/ark:/12148/bpt6k858577n(date accessed: 10.02.2019).
} 
2.La segunda dirección reflejó las posiciones de los reformadores luteranos sobre la igualdad de derechos de todas las lenguas cristianas, independientemente del grado de prevalencia ${ }^{8}$.

En otras palabras, Francia e Inglaterra medieval como dos potencias poderosas establecen el tono básico de la política lingüística destinada a imponer un idioma común y erradicar a otros con el objetivo de crear valores culturales comunes para todas las personas y su control. Fue en estos países donde comenzó a surgir la idea de una nación y la conexión entre el lenguaje y el poder se hizo tangible.

\section{Segundo período (1880 a 1848)}

En este momento, se identifican varios factores que tienen un impacto negativo principalmente en los idiomas regionales o minoritarios.

En primer lugar, la acción militar. Como saben, desde la antigüedad, los Estados poderosos intentaron imponer su idioma a los pueblos conquistados. El antiguo historiador romano, una de las personas más famosas de la antigüedad, Publio Cornelio Tácito, escribió que «el lenguaje del vencedor en boca de los vencidos es siempre el lenguaje de la esclavitud» ${ }^{9}$. Esta frase ilustra la estrecha relación entre el lenguaje y las conquistas, que se ha confirmado en la historia de muchos países. Por ejemplo, en Francia, el francés se usó para centralizar el poder político creando un idioma oficial y suprimiendo las expresiones linguiísticas locales y regionales. Fuera de él, no solo era un lenguaje diplomático y se usaba para promover el estatus internacional de Francia, sino que también se imponía a los pueblos conquistados ${ }^{10}$. Al final de su volumen sobre los períodos revolucionario y napoleónico, F. Bruno escribió: «El ejército imperial cree que el idioma francés está firmemente arraigado en las clases ricas y los círculos educados de los países que conquistaron ${ }^{11}$.

En particular, después de una exitosa campaña italiana, N. Bonaparte intentó imponer el idioma francés como idioma oficial en Italia, pero esta política provocó el patriotismo italiano ${ }^{12}$ como resultado de la lucha por la independencia, la unidad y la libertad en el país. Según F. Bruno, «el único idioma compatible con la libertad política era el idioma nacional» ${ }^{13}$. En este momento del proceso de modernización, la idea del nacionalismo está surgiendo no solo en Italia, sino también en Alemania y Polonia. Los factores que unen a las personas son el idioma y la cultura. El nacionalismo contribuye a la formación del hombre de la Nueva Era: emancipatorio, dinámico, racional ${ }^{14}$.

\footnotetext{
${ }^{8}$ KADYIROVA, N.A. Evolyutsiya protsessov po zaschite prav lingvisticheskih menshinstv v Evrope.[Elektronnyiy resurs]. Rezhim dostupa: http://sci-article.ru/stat.php?i=1454333848 (data obrascheniya: 16.11.2018).

9 O'FIAICH, T. The language and political history // A view of the Irish language. Edited by B. O'Cuiv.1969.-P.101.

${ }^{10}$ Costa de Marfil, Burkina Faso, Guinea (antes de la FAA), Mauritania (desde 1904), Nigeria, Senegal, P. Sudán (Malí).

${ }^{11}$ KOHN, H.Napoleon and the Age of Nationalism, Journal of Modern History vol. 21 no.1 (1955). - P.30.

${ }^{12}$ DUGGAN, C. A Concise History of Italy. Cambridge: University Press, 2012.-P.96.

${ }^{13}$ KOHN, H., Napoleon and the Age of Nationalism, Journal of Modern History vol. 21 no.1 (1955). - P.30.

${ }^{14}$ OBOLENSKAYA, S.V. Rozhdenie germanskoy natsionalnoy idei// Evropeyskie revolyutsii 1848 goda.

«Printsip natsionalnosti v politike i ideologii.- M.: Indrik, 2001.-S.48.
} 
En el territorio de Polonia, dividido entre Prusia, Austria y el Imperio ruso, estaba vigente la Constitución de 27 de noviembre de 1815, firmada por Alejandro I, según la cual el Polaco era oficial y el trabajo en el territorio del Reino de Polonia se realizaba en Polaco (artículo 28) ${ }^{15}$. Sin embargo, el levantamiento Novobersky de 1830 implicó la expulsión de la lengua polaca. El 14 (26) de febrero de 1832 se promulgó un estatuto Orgánico especial que proclamaba el principio de rusificación, que era la difusión de la lengua y la literatura rusas. Estas materias comenzaron a enseñarse en la escuela y en el hogar, junto con el Griego clásico y el latín, cuyo conocimiento era obligatorio ${ }^{16}$.El Polaco hablado se ha convertido en una manifestación de patriotismo y respeto por los valores tradicionales ${ }^{17}$.El multilingüismo era común entre la nobleza polaca, la intelectualidad y la burguesía. En particular, los hombres y las mujeres se comunicaron en su idioma nativo Polaco, ruso (estatal), así como en francés o Inglés, que comenzó a ser cada vez más importante como idioma de comercio.

En segundo lugar, la participación de las personas en la política. En países como Francia y Bélgica, los políticos alentaron la promoción del francés como herramienta política. En el Reino Unido de gran Bretaña, los líderes de varios movimientos ${ }^{18}$ han desempeñado un papel importante en la difusión del idioma inglés al involucrar a las masas en las elecciones parlamentarias y las reuniones de masas ${ }^{19}$. D.O'Connell, un líder político irlandés, criticó el idioma irlandés, considerándolo atrasado, e instó a los irlandeses a aprender inglés, el idioma del futuro ${ }^{20}$. Un punto de vista similar fue sostenido por W. B. Yates, enfatizando que el inglés es el idioma de la Irlanda moderna ${ }^{21}$. La publicidad fue el principal arma de los políticos. Cada vez más personas aprendieron inglés ${ }^{22}$. Las personas que promovieron asuntos nacionalistas (por ejemplo, el regreso del Parlamento, la liberación del pueblo) utilizaron el inglés como lenguaje de negociación y debate en un esfuerzo por lograr sus objetivos ${ }^{23}$. En opinión de V. Maurin, a pesar de la apelación de los líderes de varios movimientos a una especie de reemplazo sentimental

\footnotetext{
${ }^{15}$ Konstitutsionnaya Hartiya Tsarstva Polskogo 1815 goda. [Elektronnyiy resurs]. Rezhim dostupa: http://www.pereplet.ru/history/Russia/Imperia/Alexandr_I/kx1815.html(data obrascheniya: 08.02.2019).

${ }^{16}$ OTWINOWSKA, A. Cognate Vocabulary in Language Acquisition and Use: Attitudes, Awareness, Activation.[Electronic resource]. Access mode: https://books.google.it/books?id=5teOCgAAQBAJ\&printsec=frontcover\&hl=it\#v=onepage\&q\&f=false (date accessed:23.11.2018).

${ }^{17}$ DAVIES, N. 2005. God's Playground. A History of Poland in Two Volumes. Oxford: University Press. -P.442.

${ }^{18}$ Por ejemplo, El movimiento de autogobierno, el Movimiento de abolición, la liga de inquilinos, la liga de tierras.

${ }^{19}$ MAUREEN W. The decline of the Irish language // A View of the Irish language. Edited by Brian O’Cuiv. -1969.-P.89.

${ }^{20}$ BOYLAN, H. A Dictionary of Irish Biography (3rd ed.). Dublin: Gill and MacMillan. -1998. -P. 306.

${ }^{21}$ YEATS, W.B. [Electronic resource]. Access mode: The Bounty of Sweden http://www.nobelprize.org/nobel_prizes/literature/laureates/1923/yeats-lecture.html (date accessed:04.04.2019).

${ }^{22}$ MAUREEN, W. The decline of the Irish language // A View of the Irish language. Edited by Brian O'Cuiv. -1969.-P.89.

${ }^{23}$ YEATS, W.B. The Decline of the Irish Language in the Nineteenth Century.[Electronic resource]. Access mode: $\quad$ https://www.yeatssociety.com/news/2015/03/09/the-decline-of-the-irish-language-in-thenineteenth-century/ (date accessed: 31.03.2019).
} 
del nacionalismo cultural genuino, la búsqueda de características nacionales podría servir como una fuerza unificadora para superar las diferencias ${ }^{24}$.

En tercer lugar, el bajo nivel de educación. A pesar de la consolidación constitucional de la libertad lingüística ${ }^{25}$ en Bélgica en el siglo XIX, el francés prevaleció en la educación, la gobernanza, la política y la vida pública. La mayoría de los flamencos eran sin educación y pobres. Para aumentar la alfabetización de la población, la educación en las escuelas se organizó exclusivamente en francés ${ }^{26}$.En una Austria inestable y multinacional, las lenguas regionales o minoritarias fueron sistemáticamente menospreciadas en las escuelas y el Gobierno impuso sanciones a los estudiantes que hablaban sus idiomas nativos.

En Italia, especialmente en las regiones del Sur, alrededor del 75\% de la población era analfabeta. El sistema escolar estaba en mal Estado debido a la falta de fondos y maestros calificados. Con la introducción de la enseñanza escolar obligatoria, el nivel de alfabetización aumentó y muchos hablantes nativos abandonaron el idioma nativo en favor del italiano. Las minorías lingüísticas comenzaron a crear organizaciones para proteger su idioma e insistir en la autonomía.

En el Territorio del Reino de Polonia desde 1836, el conocimiento del idioma ruso para algunos sectores de la población se declaró obligatorio. En los planes de estudio, se asignaron muchas horas al estudio del idioma ruso. En las ciudades se abrieron cursos gratuitos para aprender ruso. En 1839, se formó el cuerpo de entrenamiento de Varsovia, subordinado al Ministerio ruso de educación pública.

El problema del bajo nivel de educación ha afectado a todas las partes del Reino Unido. El desempleo, la pobreza y el hambre caracterizaron la situación en este país. Los idiomas minoritarios se asociaron con algo desfavorable, como el atraso, la pobreza, la falta de poder, lo que provocó su declive y los hizo menos populares. Aunque el historiador D. L. Campbell argumenta que no hay conexión entre el lenguaje y la pobreza de la manera en que el Reino Unido tenía muchos monoglots de habla inglesa impecables que eran pobres ${ }^{27}$. El historiador C. Whiters sugiere que el impulso de la caída del gaélico fue su pequeño papel en la vida pública, que fue el resultado de una larga división del idioma y el poder: control político, prestigio cultural y estatus social ${ }^{28}$.

En el Gobierno Escocés, D. Ramsey, un político del partido liberal, enfatizó la importancia del inglés como idioma de enseñanza y alentó a los montañeses a aprender este idioma para mejorar su posición, ya sea en su tierra natal o en otros países ${ }^{29}$.D.

\footnotetext{
${ }^{24}$ MAUREEN W. The decline of the Irish language // A View of the Irish language. Edited by Brian O'Cuiv. -1969.-P.90.

${ }^{25}$ En el artículo 30 de la Constitución belga de 7 de febrero de 1831, aprobada por la Asamblea nacional, se establecía el carácter no vinculante del uso de los idiomas. Esto sólo podía regirse por la ley y únicamente por los actos de las autoridades públicas y los procedimientos judiciales. Los ciudadanos podían usar cualquier idioma a su discreción, garantizando así la libertad lingüística.

${ }^{26}$ RUYS, M. (1981) Die Flamen. Ein Volk in Bewegung, eine werdende Nation. Tielt. -P.46.

${ }^{27}$ CAMPBELL, J. L., (1945) Gaelic in Scottish Education and Life: Past, Present and Future. Edinburgh: W. \& AK Johnston.-P.59-60.

${ }^{28}$ WITHERS, C.W.J., Gaelic in Scotland 1698-1981. Edinburgh: John Donald Publishers LTD.1984.P.241.

${ }^{29}$ NICOLSON, A (1866) Report on the State of Education in the Hebrides. [Electronic resource].Access mode:https://books.google.no/books?hl=no\&lr=\&id=ixZLAQAAMAAJ\&oi=fnd\&pg=PA1\&dq=report+o
} 
Sinclair, recomendó adoptar un nuevo idioma: el inglés como idioma de aprendizaje ${ }^{30}$. D. Bowie declaró: «Espero que el gaélico sea explotado hasta el punto en que se convierta en un idioma muerto y que el inglés se convierta en el idioma predominante de un extremo del país al otro» ${ }^{31}$. C. Chisholm, ex presidente de la sociedad gaélica en Londres, describió su impresión de Ellis, un miembro escocés del Parlamento: «El Sr. De sus labios no se desprendió una sola palabra que pudiera interpretarse como negligencia o falta de respeto hacia los montañeses ${ }^{32}$.Se puede suponer que no todos los miembros del Parlamento compartían una actitud negativa hacia el gaélico, pero prevaleció. Como resultado de las discusiones, se creó un Comité especial que comenzó a distribuir folletos sobre el papel negativo del gaélico en el Reino Unido, pero los montañeses trataron de corregirlo ${ }^{33}$.

Numerosas protestas por la calidad de la educación en Gales en las décadas de 1830 y $1840^{34}$, así como el discurso de W. Williams, Miembro del Parlamento de Conventry en la Cámara de los Comunes el 16 de marzo de 1846 sobre el Estado de la educación en Gales, empeoraron las cosas para los galeses. En Gales, se estableció una Comisión compuesta por tres jóvenes abogados. Para el 1 de abril de 1847, habían presentado un informe sobre el idioma galés. Según los miembros de la Comisión, el idioma galés era un gran inconveniente y citó un gran número de cartas de sacerdotes anglicanos que argumentaban que la posición moral y material de los galeses no podía mejorarse sin la introducción del inglés. Los efectos psicológicos asociados con el uso del idioma galés dañaron la psique y la naturaleza general de hombres y mujeres ${ }^{35}$.En las escuelas se fomentó activamente la denuncia de niños de habla galesa. A estos niños se les colgaban carteles con las palabras "no al galés", consideradas una gran vergüenza ${ }^{36}$.Por lo tanto, los galeses han perdido el respeto por su lengua materna y creen que solo pueden mejorar su posición a través de la educación y la capacidad de comunicarse en inglés.

A principios del siglo XIX, en Irlanda, las escuelas de cobertura ${ }^{37}$ existentes eran vistas como insatisfactorias debido a las condiciones físicas primitivas, la baja capacitación de los maestros y el plan de estudios obsoleto. En estas escuelas se impartían

$\mathrm{n}+$ the+state+of+education+in+the+hebrides+by+alexander+nicolson\&ots $=$ f22yrxDL7W\&sig $=0 \mathrm{EcXEd} \mathrm{v}$ Tgf_vjt3oBvtVIvrTFQ\&redir_esc=y\#v=onepage\&q \&f=false(Date accessed: 24.03.2019).

${ }^{30}$ BROWN, I. (2006). Edinburgh History of Scottish Literature: Enlightenment, Britain and Empire (17071918). Edinburgh: Edinburgh University Press. -P.29.

${ }^{31}$ First Report on the Select Committee on Emigration in Scotland. The House of Commons.1841. -P.19.

${ }^{32}$ CHISHOLM, C. The Clearance of the Highland Glens (1878). [Electronic resource]. Access mode: http://www.electricscotland.com/history/articles/clearance.htm (Date accessed: 24.03.2019).

${ }^{33}$ First Report on the Select Committee on Emigration in Scotland. The House of Commons. 1841. -P.19.

${ }^{34}$ Llyfrgell Genedlaethol Cymru - The National Library of Wales (a). The Blue Books of 1847. n.d. 9 May

2016. [Electronic resource]. Access mode: https://www.llgc.org.uk/discover/digital-gallery/printedmaterial/the-blue-books-of-1847/>.(Date accessed: 27.03.2019).

${ }^{35}$ DAVIS J. The Welsh language: A History. The University of Welsh Press.2014. - P.192.

36 BALL, M, MULLER N. The Celtic Languages. Routledge. [Electronic resource]. Access mode: https://books.google.it/books?id=lDZASvUihk0C\&pg=PT663\&lpg=PT663\&dq=1846+by+William+Will iams++welsh+language\&source=bl\&ots=Z9ft59DUiT\&sig=ACfU3U2JDwY27H1 ADNUViMMPaetCxi D4Hw\&hl=en\&sa=X\&ved=2ahUKEwi4nuuHn6LhAhVCKuwKHRj9ACEQ6AEwB3oECAgQAQ\#v=on epage \&q=1846\%20by $\% 20 \mathrm{William} \% 20 \mathrm{Williams} \% 20 \% 20 \mathrm{welsh} \% 20$ language $\& \mathrm{f}=$ false (Date accessed: 27.03.2019); Chisholm, C. The Clearance of the Highland Glens (1878). [Electronic resource]. Access mode: http://www.electricscotland.com/history/articles/clearance.htm (Date accessed: 24.03.2019).

${ }^{37}$ Escuelas para los pobres al aire libre. 
las siguientes disciplinas: lectura de Inglés, escritura y aritmética ${ }^{38}$.La lucha entre los evangélicos protestantes, que vieron el idioma irlandés como una herramienta de enseñanza Evangélica, y la iglesia católica llevó a la creación del sistema nacional de educación en 1831 y la prohibición de la enseñanza del idioma irlandés. La eliminación del analfabetismo en Inglés se ha convertido en el objetivo principal del nuevo sistema educativo, que ha tenido un efecto trágico y devastador en el uso de la lengua materna.

En Cuarto lugar, la tensa situación económica. Las personas se vieron obligadas a buscar trabajo dentro y fuera del país. Por ejemplo, para los irlandeses, la emigración a Inglaterra y América del Norte fue una razón para abandonar su lengua materna. Gracias a su conocimiento del idioma inglés, los trabajadores irlandeses a menudo ganaban significativamente más de los terratenientes ingleses e anglo-irlandeses que de los monoglots que hablaban gaélico ${ }^{39}$. El desarrollo y desarrollo de recursos naturales por parte de la gente, el establecimiento de fábricas de acero y minas de carbón condujo a la inmigración interna, principalmente en el sureste y el Norte de Gales. Si pocos inmigrantes aprendían galés para encajar en la sociedad, la mayoría continuaba hablando inglés, lo que obligaba a los galeses a aprender y usar inglés diariamente en lugar de galés $^{40}$. Poco a poco, el inglés se extendió por todo Gales.

Durante el período que se examina, los países europeos han adoptado políticas de asimilación respecto de las lenguas regionales o minoritarias. Las principales causas son: las consecuencias de las hostilidades, la participación de las personas en la política, el bajo nivel de educación y la tensa situación económica. En primer lugar, como resultado de las guerras Napoleónicas, se producen cambios territoriales en los países de Europa y los idiomas de los Estados poderosos (por ejemplo, el francés) se imponen a los pueblos conquistados, a quienes se les prohíbe usar y hablar sus idiomas nativos. En segundo lugar, las actividades de los políticos europeos tienen como objetivo mantener y utilizar activamente los idiomas oficiales de los Estados en la vida pública. La población comienza a mostrar interés en el estudio de estos idiomas, para participar en varias reuniones masivas. En tercer lugar, para mejorar el nivel de educación, algunos Estados imponen restricciones al uso de idiomas regionales o minoritarios, y la mayoría impone sanciones en las escuelas. El idioma de enseñanza en las escuelas y universidades se convierte en el idioma oficial del país. En cuarto lugar, para mejorar la calidad de vida, las personas abandonan sus lugares de origen, cambian de lugar de trabajo y comienzan a aprender el idioma oficial del país.

\section{Tercer período (1848 a 1918)}

Como se sabe, de 1848 a 1849, Europa estuvo envuelta en levantamientos revolucionarios y nacionales, llamados «primavera de los pueblos». La fuerza motriz de los levantamientos fueron los sectores de la sociedad que buscaban participar en el gobierno, mejorar sus condiciones de vida y las nacionalidades que luchaban por la

\footnotetext{
${ }^{38}$ MAUREENW. The decline of the Irish language // A View of the Irish language. Edited by Brian O'Cuiv. -1969.-P.89.

39 CROWLEY, The Politics of Language in Ireland, The Proceedings of the Barra Ó Donnabháin Symposium. -2007. -P.134.

${ }^{40}$ SYLVAIN S. The role and importance of the Welsh language in Wales's cultural independence within the United Kingdom. [Electronic resource]. Access mode: https://dumas.ccsd.cnrs.fr/dumas00719099/document (Date accessed: 05.04.2019).
} 
autonomía, la independencia o la unificación dentro de un solo Estado ${ }^{41}$. Por lo tanto, en Europa existían tres tendencias revolucionarias relacionadas con el sistema político, social o nacional.

En febrero de 1848 comenzó en París la revolución de febrero, cuya premisa, además de la lucha de clases entre la burguesía y el proletariado, era la cuestión nacional. En este tema, las ideas de I. G. Herder desempeñaron un papel especial. Propuso la tesis de que «La humanidad como algo universal se encarna en Naciones históricamente separadas. Los pueblos con diferentes idiomas tienen una expresión diversa de un principio Divino único y cada pueblo contribuye a su existencia ${ }^{42}{ }_{\gg}$. Cada pueblo debe tener unidad e identidad en la cultura, en el idioma.

Una serie de disturbios estallaron en el territorio del Imperio Austríaco para resolver la cuestión nacional. Los húngaros se opusieron firmemente al fortalecimiento de la posición de la lengua alemana en la comunicación administrativa y militar y la política de centralización para modernizar las tierras de los Habsburgo ${ }^{43}$.La crisis húngara afectó mucho más al poder del emperador, ya que puso en peligro los cimientos del Imperio Austríaco ${ }^{44}$.Como creía el emperador, la unidad y la homogeneidad del ejército no deben estar en peligro a toda costa y el idioma del comando debe ser uno, es decir, alemán. En el ejército, había un problema particular en la comunicación debido a la composición multinacional de soldados que no dominaban el idioma alemán. I.Szecheni y L. Kashut iniciaron una serie de proyectos, incluido un movimiento de renacimiento nacional para hacer que el idioma húngaro sea adecuado para gobernar el país. La derrota en la guerra Austro-italo-francesa reforzó el trabajo de los movimientos nacionales. Como resultado, en 1867 se estableció el Imperio austrohúngaro como un gran compromiso que dio al pueblo Húngaro una posición casi igual en el Imperio Austríaco. La Constitución del Imperio Austríaco de 21 de diciembre de 1867, promulgada por Francisco José I, en el párrafo 2 del artículo 8, otorgaba el derecho a la preservación y el desarrollo de la nacionalidad y el idioma a todas las minorías étnicas, los mismos derechos a todos los idiomas utilizados en las regiones en las esferas de la educación, la administración pública y la vida pública, y el derecho a la educación en su propio idioma a las comunidades étnicas sin la necesidad de adquirir un segundo idioma utilizado en la provincia ${ }^{45}$. En 1868, el Reino de Hungría, que se convirtió en una entidad Autónoma dentro del Imperio de los Habsburgo, aprobó la Ley de ciudadanía (XLIV), que fue la primera legislación en Europa que codificó los derechos de los grupos étnicos. El idioma oficial del Estado fue proclamado húngaro. Las leyes se han traducido y publicado en idiomas minoritarios (párr.1). Los funcionarios municipales se comprometieron, en la medida de lo posible, a utilizar el idioma de esos órganos en los contactos oficiales con las aldeas, las

\footnotetext{
${ }^{41}$ The Spring of Nations (1848). [Electronic resource]. Access mode: http://grial4.usal.es/MIH/SpringNations2/en/presentation.html (Date accessed: 30.04.2019).

${ }^{42}$ HERDER J.G. Briefe zur Beforderung der Humanitat. Rudolstadt, O.D.-P.213-216.

${ }^{43}$ WINTER, E. Frühliberalismus in der Donaumonarchie: Religiöse, nationale und wissenschaftliche Strömungen von 1790-1868. Berlin: Akademie Verlag. -1968. -P.23.

${ }^{44}$ TSCUPPIK, K. (1928). Franz Joseph I., Der Untergang eines Reiches. Hellerau bei Dresden: AvalunVerlag. -P.247.

45 The Austrian Constitution of 1867. Walter Farleigh Dodd, ed., Modern Constitutions: A Collection of the Fundamental Laws of Twenty-two of the Most Important Countries of the World, With Historical and Bibliographical Notes. Chicago: The University of Chicago Press, 1909.
} 
comunidades, las sociedades, las instituciones y los particulares (párr.6). En las reuniones del pueblo, los pueblos eran libres de elegir el idioma (párr.20). La apertura de escuelas que utilizaban idiomas minoritarios era gratuita y las escuelas tenían los mismos derechos que las escuelas públicas similares (párr.27) ${ }^{46}$. Esta ley permitió el uso de cualquier otro idioma regional como idioma oficial tanto en la administración pública, el poder judicial, las organizaciones de la iglesia como en la educación a nivel local. Las lenguas regionales o minoritarias han sido ampliamente reconocidas gracias a estas normas. Este Estado de cosas continuó hasta el colapso del Imperio austrohúngaro.

Los Estados alemanes y la Unión de príncipes alemanes resultaron ser el centro del «nacionalismo romántico», cuyo representante fue I. G. Fichte. Escribió que «la unidad ya ha surgido, se ha completado y ahora existe, es la unidad de la lengua y la cultura de los alemanes, sobre todo la lengua que separa de otros pueblos. La vida de una persona se vuelve verdaderamente completa y significativa cuando vive en un país donde tanto la nación cultural como la nación estatal son idénticas» ${ }^{47}$. Las masas populares alemanas buscaban la unificación de Alemania. Usando la idea liberal-germano-nacional, O. Bismarck, como resultado de tres guerras, logró unir a Alemania. La idea nacional tomó la forma del nacionalismo imperial, dio lugar a la glorificación de la gran potencia hegemónica y a la idea de expansión y pangermanización. En la mente de las masas, nació el odio hacia los franceses, judíos, polacos y eslavos ${ }^{48}$.

Las revoluciones europeas influyeron en la actividad de los polacos y otras poblaciones en el territorio de la antigua Mancomunidad Polaco-lituana, que pertenecía al Imperio ruso. El 14 de marzo de 1848, el emperador Nicolás I publicó un manifiesto en el que definía claramente su posición con respecto a las «rebeliones y despoblaciones» que surgieron en Europa. En 1863 estalló la revuelta de enero para restaurar la Mancomunidad Polaco-lituana, que terminó con la pérdida de los rebeldes y el fortalecimiento de la política anti-lingüística contra los polacos. Los polacos se vieron obligados a usar el idioma ruso y hicieron esfuerzos significativos para preservar la identidad nacional polaca.

En Italia, hubo levantamientos en Lombardía, Venecia, Milán, Palermo y luego en toda la isla, que infligieron un duro golpe al poder del Imperio de los Habsburgo. Como resultado de los levantamientos, el Rey K. Albert adoptó el estatuto Albertino (Piamontés), cuyo artículo 62, además del reconocimiento oficial del italiano, permitía el uso del francés a los miembros de los distritos francófonos ${ }^{49}$.En algunas regiones, los idiomas nacionales han sido prohibidos.

En Bélgica, el movimiento flamenco defendió la defensa de la lengua holandesa. Se supone que los instigadores de este movimiento fueron Jan Frans Willems y Hendrik

\footnotetext{
${ }^{46}$ PASCU, M.: A History of Transylvania. [Electronic resource]. Access mode: http://www.hungarianhistory.com/lib/pas/pas14.htm (Date accessed: 30.04.2019).

${ }^{47}$ NIPPERDEY, T. Nachdenken uber die Deutsche Geschichte. Munchen, 1986.

${ }^{48}$ OBOLENSKYA S. V. Germanskaya natsionalnaya ideya na sluzhbe Bismarka i ee sudba v XX veke// Evropeyskie revolyutsii 1848 goda. «Printsip natsionalnosti v politike i ideologii.-M.: Indrik, 2001.-S.7677.

49 Statuto Albertino. [Electronic resource]. Access mode: http://www.quirinale.it/allegati_statici/costituzione/Statutoalbertino.pdf (Date accessed: 08.11.2018)
} 
Konjans $^{50}$. Este movimiento se desarrolló en un momento en que las lenguas mismas sirvieron como "marcadores de identificación" de los habitantes del Estado. En respuesta al movimiento flamenco, se creó el valón. Como señala P. H. Nelde, la lucha de los dos movimientos fue «un conflicto no entre lenguas, sino entre hablantes nativos y comunidades lingüísticas» ${ }^{51}$.

La primera victoria del movimiento flamenco fue el reconocimiento por las autoridades belgas del carácter bilingüe de todo el Estado mediante la promulgación de las siguientes leyes:

1) La Ley de Coremans (Wet-Coremans op Het Gerecht), de 17 de agosto de 1873, sobre el uso del idioma holandés en la justicia en Flandes, firmada por Leopoldo II $^{52}$.En las provincias flamencas, el juez o el presidente del jurado, al explicar sus derechos y obligaciones, se ha comprometido a interrogar al acusado sobre el grado de competencia lingüística del proceso. Si el acusado no hablaba el idioma, se le permitía hablar en su propio idioma. En el caso de dos o más personas que no dominan el idioma del proceso, la administración de justicia se llevó a cabo en su lengua materna, el holandés.

2) La Ley de Laata (Wet-de Laet) de 1878 sobre el uso de ambos idiomas (holandés, francés) en el ámbito administrativo ${ }^{53}$. Con la aprobación de esta ley, los informes de los funcionarios públicos comenzaron a redactarse en holandés o en dos idiomas. Los funcionarios públicos se comprometieron a utilizar el holandés en correspondencia con las autoridades locales o los ciudadanos a petición de estos últimos.

3) La Ley de Vigne-Coremans de 1883 (Wet-de Vigne-Coremans) sobre el reconocimiento del idioma holandés en la educación secundaria ${ }^{54}$. El holandés ha sido declarado el idioma oficial de las unidades preparatorias de las escuelas secundarias en Flandes. Las primeras disciplinas en holandés fueron los cursos de idiomas ${ }^{55} \mathrm{y}$ al menos las otras dos materias. Los estudiantes comenzaron a aprender los términos técnicos de matemáticas, física, historia y geografía en holandés ${ }^{56}$.De ello se deduce que la protección de los derechos lingüísticos de los holandeses en Flandes se limitaba a los ámbitos de la justicia, la educación y la administración.

Después de años de luchas sociales, políticas, culturales y económicas, el gobierno otorgó un estatus oficial adicional al idioma holandés. En ambos idiomas se emitieron monedas (1886), billetes (1888) y sellos postales (1891). En 1887, el Rey Leopoldo II pronunció por primera vez un discurso en holandés, seguido de un discurso en holandés

\footnotetext{
${ }^{50}$ ULRIKE V., Hüning M. One Nation, One Language? The Case of Belgium. [Electronic resource]. Access mode: http://www.academia.edu/1056036/One_nation_one_language_The_case_of_Belgium (Date accessed: 14.10.2018).

${ }^{51}$ NELDE, P.H., Language in Contact and Conflict: The Belgian Experience and the European Union, in languages in contact and conflict, contrasting experiences in the Netherlands and Belgium//Sue Wright ed., Multilingual Matters Ltd 1995. -P.65,66.

${ }^{52}$ GOETHEM, V. H., De taaltoestanden in het Vlaams-Belgisch gerecht, 1795-1935, Verhandelingen van de Koninklijke Academie voor Wetenschappen, Letteren en Schone Kunsten van Belgïe, 1990. -P.162-178. ${ }^{53}$ GOETHEM, V. H., De taaltoestanden in het Vlaams-Belgisch gerecht, 1795-1935, Verhandelingen van de Koninklijke Academie voor Wetenschappen, Letteren en Schone Kunsten van Belgïe, 1990.-P.162-178. ${ }^{54}$ DENECKERE, G.1900: België op het breukvlak van twee eeuwen//Lannoo Uitgeverij, 2006.-P.186. 55 Id.

${ }^{56}$ HOOGHE, L., Belgium: Hollowing the Center, in federalism. unitarism, and territorial cleavages (Ugo Amoretti \& Nancy Bermeo eds., Johns Hopkins Press 2002). [Electronic resource]. Access mode: http://www.unc.edu/ hooghe/assets/docs/books/princeton_finaldraft.pdf (Date accessed: 09.11.2018).
} 
en el Parlamento belga ${ }^{57}$. Gracias a la Ley de igualdad de 1898, el holandés se convirtió en el idioma oficial en Bélgica junto con el francés. Los textos legislativos en ambos idiomas recibieron la misma condición jurídica.

El Estado que no participó en las revoluciones europeas de 1848-1849 fue el Reino Unido de Gran Bretaña e Irlanda. En el territorio del país, los movimientos nacionales comenzaron a crearse activamente. En 1893, D. Hyde, E. McNeil, D. Comin, O. O'Grooney fundaron la Liga Gaélica. Este movimiento lingüístico tenía los siguientes objetivos: proteger el idioma irlandés, crear literatura en irlandés ${ }^{58}$. T. O'Hailin describe a la liga Gaélica como la única organización que buscaba hacer del presente una extensión racional del pasado. Sus miembros se dieron cuenta de que Irlanda tenía su propio pasado, su propia historia y literatura ${ }^{59}$.La política educativa de esta liga era doble: los estudiantes se comprometían a Leer, escribir en irlandés, aprender inglés y otras materias en irlandés si su lengua materna era el irlandés. De lo contrario, este último se enseñó desde la primera infancia y como parte del programa escolar por un costo adicional ${ }^{60}$. En 1901, gracias a los esfuerzos de la liga Gaélica, el gobierno nacional devolvió el irlandés como idioma de enseñanza ${ }^{61}$.

En Francia, el sistema educativo ha sufrido una mayor centralización lingüística. El principio de prioridad del francés sobre todos los demás idiomas en los documentos legales se vio reforzado por las decisiones de 1859 y 1875 . En virtud de las leyes Jules Ferry de 1881-1886, la educación primaria fue declarada obligatoria, laica y libre, pero el idioma de enseñanza siguió siendo el francés.

En el Reino Unido de Gran Bretaña e Irlanda, el resultado de la labor de los comités y Gobiernos especiales de Escocia y Gales fue la aprobación de las leyes de educación (Ley de educación de 1872 en Escocia, Ley de educación de 1870 y Ley de educación de 1889 en Gales). El objetivo de las leyes era educar a los estudiantes en inglés y modernizar el sistema educativo ${ }^{62}$. Debido a la falta de apoyo de los políticos y las personas en el sistema educativo, las actitudes negativas hacia el gaélico y el galés en la sociedad, la educación bilingüe no se consideró ${ }^{63}$. Muchas personas consideraron que esta ley era problemática porque no podían hablar y / o leer inglés. Según K. McKinnon, la Ley de educación de 1872 en Escocia interrumpió el movimiento hacia la alfabetización gaélica y produjo generaciones de personas prácticamente analfabetas en su lengua materna y

\footnotetext{
${ }^{57}$ VANDERSTAPPEN, T. The Flemish Movement: How language shaped Belgium. [Electronic resource]. Access mode: http://www.brusselstimes.com/magazine2/12050/the-flemish-movement-how-languageshaped-belgium (Date accessed: 09.11.2018).

${ }^{58}$ FOSTER, R.F., Modern Ireland 1600-1972, London 1988, pp 447-8; S.J. Connolly (ed.), The Oxford companion to Irish history, Oxford 1998.-P. 215, 253, 338-9.

${ }^{59}$ O'HAILIN, T. Irish revival movements // A view of the Irish language. Edited by B. O'Cuiv. -1969.P.96.

${ }^{60}$ O'HAILIN, T. Irish revival movements // A view of the Irish language. Edited by B. O'Cuiv. -1969.P.97.

${ }^{61}$ HINDLEY, R. 1990. The Death of the Irish language: A qualified obituary London: Routledge. -1990.P.24.

${ }^{62}$ Education: Primary Public Education- National Schools from 1831. Encyclopedia of Irish History and Culture. [Electronic resource]. Access mode: https://www.encyclopedia.com> (Date accessed: 01.04.2019).

${ }^{63}$ SMITH, J. A., (1968) «The Position of Gaelic and Gaelic culture in Scottish Education in Thomson», D.S., \& Grimble, I. (ed), (1968) The Future of the Highlands. London: Poutledge \& Kegan Paul. - P.64.
} 
capacitadas para que su cultura no tuviera ningún valor ${ }^{64}$. En virtud de la siguiente Ley de educación de 1889, se establecieron escuelas secundarias en Gales, pero sólo en algunas de ellas se consideró que el idioma galés era una ocupación optativa. Por lo tanto, estas leyes deben considerarse como anti-lingüística debido a la asimilación de la cultura y el idioma inglés, mostrando un bajo respeto por las lenguas minoritarias, ignorando total o parcialmente.

En Italia, durante el reinado de Víctor Manuel II (1861-1878), la formación de la política lingüística fue una de las prioridades del nuevo Reino. El objetivo de la normalización de los diferentes idiomas nacionales, que se llevó a cabo mediante la introducción de la lengua italiana estándar, fue garantizar la plena comprensión de todas las leyes italianas y la capacidad de los funcionarios públicos y maestros para trabajar ${ }^{65}$, así como reducir el analfabetismo. En las regiones se han establecido escuelas financiadas por el Estado para enseñar italiano. Por ejemplo, en el momento de la introducción del italiano, solo el 18 por ciento de los residentes del valle de Aosta hablaban italiano $^{66}$.Como señala M. Cortelazzo en su libro «El comienzo crítico del estudio de los dialectos italianos», la difusión del italiano dependía del grado o la calidad de la enseñanza $^{67}$.Sin embargo, la enseñanza en italiano era casi imposible, ya que los estudiantes no entendían a sus maestros, quienes, según D. Mauro, «no sabían italiano o no querían tomarlo» ${ }^{68}$. En el valle de Aosta, el francés fue prohibido en las escuelas en 1879 y en los tribunales en 1880. Dos tercios de los habitantes del valle de Aosta se fueron a Francia.

Por lo tanto, este período se caracteriza por el auge del nacionalismo cultural y político. En los países comenzaron a crearse movimientos nacionales, partidos para abolir los deberes feudales, los pagos y la unificación de los grupos étnicos. Las revoluciones europeas («primavera de los pueblos») sirvieron como una especie de medio práctico para implementar una idea nacional que fue derrotada, pero brevemente. Los disturbios que tuvieron lugar en el segundo tercio del siglo 19 dieron resultados positivos. Por ejemplo, en Bélgica comenzó a formarse el pluralismo lingüístico, en Austria-Hungría se adoptaron regulaciones liberales contra las minorías lingüísticas. En el Reino Unido de Gran Bretaña e Irlanda, en respuesta a la política de asimilación en su territorio con respecto a las lenguas regionales o minoritarias, los movimientos nacionales comenzaron a ganar impulso. Las reformas educativas adoptadas por los países europeos tenían como objetivo establecer un idioma dominante (inglés, francés, italiano), prohibir o limitar el uso del resto.

\footnotetext{
${ }^{64}$ MACKINNON, K. The lion's tongue: the story of the original and continuing language of the Scottish people. Inverness: Club Leabhar. -1974. -P.54.

${ }^{65}$ SERIANNI, L. La Lingua nella Storia d'Italia. Milan: Società Dante Alighieri, Libri Scheiwiller, 2002. -P.293,341.

${ }^{66}$ Italy: Aostans. [Electronic resource]. Access mode: https://minorityrights.org/minorities/aostans/(Date accessed: 10.01.2019).

67 CORTElazZO, M. Avviamento Critico Allo Studio Della Dialettologia Italiana. Vol. III. Pisa:Pacini,1972. -P.14.

${ }^{68}$ MAURO, D.T. Storia Linguistica Dell'Italia Unita. [Electronic resource]. Access mode: https://www.laterza.it/index.php?option=com_laterza\&task=schedalibro\&isbn=9788842096092(Date accessed: 23.11.2018).
} 


\section{Cuarto período}

La cuarta etapa de la evolución de la política lingüística comienza después del final de la primera guerra mundial. Tras la guerra, cuatro poderosos imperios dejaron de existir. Como resultado de los cambios territoriales en Finlandia, Lituania, Polonia, Hungría, Letonia, Checoslovaquia, Estonia y otros países, se declaró la independencia. Las personas que formaban la mayoría en un Estado ahora eran una minoría en otro (por ejemplo, los húngaros en Checoslovaquia y Rumania, los alemanes en el oeste de Polonia). Para protegerlos, se celebró la conferencia de paz de París de 1919, en la que los países decidieron crear la sociedad de Naciones como organización Intergubernamental para el mantenimiento de la paz y la seguridad, elaboraron proyectos de tratados de paz con Alemania (tratado de paz entre las potencias aliadas y Unidas y Alemania de 28 de junio de 1919), con Austria (Sen - Tratado de paz de Germán de 10 de septiembre de 1919 ), con Bulgaria (Tratado de paz de Neuilly de 27.11.1919), con Hungría ( Tratado de paz de Trianon de 4.06.1920), con el Imperio otomano (Tratado de paz de Sèvres de 10 de agosto de 1920 ). Además de los tratados de paz, en el marco de la organización mencionada se concertaron tratados especiales sobre minorías con Polonia (1919), Checoslovaquia (1919), el Estado Serbo-Croata-Esloveno (1919), Rumania (1919) y Grecia (1920); las declaraciones proclamadas en el Consejo de la sociedad de las Naciones por Albania (1921), Lituania (1922), Letonia (1923), Estonia (1923), el Iraq (1932) y Finlandia (sobre las minorías en las islas Åland) (1921); la convención Polaco-Danzig (1920), la convención germano-polaca sobre la alta Silesia (1922), la convención sobre Memel (1924).

$\mathrm{Al}$ analizar los tratados de paz, deben destacarse las principales disposiciones:

1) la obligación de los Estados de incluir en el tratado con las principales potencias aliadas y Unidas disposiciones para proteger los intereses de los habitantes que difieran de la mayoría de la población por raza, idioma y religión (artículo 46 del Tratado de Neis, de 29 de noviembre de 1919, artículos 51, 57, 60 del Tratado de Paz de Saint - Germain, de 10 de septiembre de 1919, artículos 44, 47 del Tratado de paz de Trianon, de 10 de septiembre de 1919, artículos 86, 93 del Tratado de paz de Sèvres, de 10 de agosto de 1920 y tratado de Paz entre las potencias aliadas y Unidas y Alemania del 28 de junio de 1919);

2) obligación de garantizar la plena y plena protección de la vida y la libertad de todos los habitantes sin distinción por motivos de nacimiento, nacionalidad, idioma, raza o religión (artículo 50 del Tratado de Neuis, de 29 de noviembre de 1919, artículo 63 del tratado de Paz de Saint - Germain, de 10 de septiembre de 1919, artículo 55 del Tratado de paz de Trianon, de 10 de septiembre de 1919, artículo 141 del Tratado de paz de Sèvres, de 10 de agosto de 1920);

3) la ausencia de restricciones al libre uso de cualquier idioma por parte de cualquier ciudadano (en las relaciones personales, en el comercio, en la religión, en la Prensa o en publicaciones de cualquier tipo o en reuniones públicas), así como la concesión a los ciudadanos que no dominen el idioma oficial, en caso de que se determine el hecho, de la posibilidad apropiada de utilizar el idioma nativo en forma oral y escrita ante los tribunales (Artículo 53 del tratado de NAIS, de 29 de noviembre de 1919, artículo 66 del Senado - Tratado de paz de Germán, de 10 de septiembre de 1919, artículo 58 del Tratado de paz de Trianon, de 10 de septiembre de 1919, artículo 145 del Tratado de paz de Sèvres, de 10 de agosto de 1920); 
4) dar a los ciudadanos que pertenecen a minorías raciales, religiosas o lingüísticas el mismo trato y seguridad legal y de hecho que a otros ciudadanos(en particular, el derecho a establecer, administrar y controlar, por su cuenta, instituciones de beneficencia, religiosas y sociales, escuelas y otras instituciones educativas con el derecho a utilizar libremente su lengua materna)(Artículo 54 del Tratado de NAIS, de 29 de noviembre de 1919, artículo 67 del Senado - Tratado de paz de Germán, de 10 de septiembre de 1919, artículo 58 del Tratado de paz de Trianon, de 10 de septiembre de 1919, artículo 147 del tratado de paz de Sèvres, de 10 de agosto de 1920);

5) otorgar a las minorías una parte justa de la utilización de las sumas aportadas con cargo a los fondos públicos en el marco de los presupuestos estatales, municipales o de otro tipo para fines educativos, religiosos o caritativos en ciudades y zonas donde una proporción significativa de ciudadanos pertenece a minorías raciales, religiosas o lingüísticas; garantizar en el sistema educativo del Estado los medios adecuados para que los niños reciban enseñanza en su idioma materno en las escuelas primarias (artículo 55 del Tratado de Neuis, de 29 de noviembre de 1919, artículo 68 del Tratado de Paz de Saint - Germain, de 10 de septiembre de 1919, artículo 59 del Tratado de paz de Trianon, de 10 de septiembre de 1919, artículo 147 del Tratado de paz de Sèvres, de 10 de agosto de 1920).

Sobre la base de estos documentos, los Estados recién formados consagraron las disposiciones sobre las minorías en sus propias constituciones y leyes. Por ejemplo, en el artículo 113 de la Constitución de la República de Weimar, de 11(14) de agosto de 1919, se estipula que las partes de habla extranjera de la población del Reich no deben verse perjudicadas por medidas legislativas y administrativas en su libre desarrollo nacional, en particular en el uso de su lengua materna en la enseñanza, la administración interna y los procedimientos judiciales ${ }^{69}$.En el artículo 110 de la Constitución de Polonia, aprobada el 17 de marzo de 1921 por el Sejm Constituyente, los ciudadanos polacos pertenecientes a minorías nacionales, religiosas o linguiísticas, se garantizaba el derecho al libre uso de su idioma en instituciones de beneficencia, religiosas y sociales, escuelas y otras instituciones educativas, así como el derecho a su establecimiento, control y gestión ${ }^{70}$. La Ley de 26 de septiembre de 1922 sobre los fundamentos de la autonomía general del Voivodato y, en particular, de los voivodatos de Lviv, Tarnopolski y Stanislavski estableció que las autoridades, incluidas las autoridades judiciales que utilizaron el idioma polaco en la producción nacional, pueden responder a las declaraciones en el idioma de las partes, es decir, en polaco o en ruso. Los órganos de autogobierno tenían el derecho de determinar por sí mismos los idiomas de la administración interna y la enseñanza en las escuelas. Las leyes, incluidas las de voivodato, las órdenes, las decisiones y otros actos estatales, también debían publicarse en el idioma rutinario ${ }^{71}$. La resolución № XLL del Consejo de gobierno Revolucionario de la República Soviética de Hungría, de 7 de abril de 1919, estableció que todos los órganos están obligados a aceptar declaraciones

\footnotetext{
${ }^{69}$ Constitución del Reich Alemán de 1919. [Electronic resource]. Access mode: http:// www.documentarchiv.de/wr/wrv.html\#ERsTER_AbsCHNITT02. (Date accessed: 06.12.2018).

${ }^{70}$ Constitution of the Republic of Poland, March 17 of 1921. [Electronic resource]. Access mode:http://libr.sejm.gov.pl/tek01/txt/kpol/e1921.html (Date accessed: 08.11.2018).

${ }^{71}$ DZIENNIK, U. RP 1922. Nr 90. Poz. 829. [Electronic resource]. Access mode: http://prawo.sejm.gov.pl/isap.nsf/download.xsp/WDU19220900829/O/D19220829.pdf(Date accessed: 08.02.2019).
} 
redactadas en cualquiera de los idiomas utilizados en Hungría y a entregar las decisiones en el idioma de la declaración. El párrafo 2 del artículo 8 de la ley constitucional Federal de Austria de 1920 garantizaba que «la República (federación, tierras y municipios) reconoce la creciente diversidad lingüística y cultural que se expresa en los grupos étnicos autóctonos. El idioma y la cultura, la existencia y la preservación de estos grupos étnicos deben ser respetados, asegurados y alentados ${ }^{72}$. El análisis de los documentos anteriores muestra la consolidación de la libre utilización de las lenguas regionales o minoritarias en las diversas esferas de la vida de la sociedad, así como la prohibición de establecer restricciones legales a su uso, desarrollo y enseñanza.

El tratado de Trianón obligaba a Hungría a garantizar la condición jurídica de las minorías ${ }^{73}$. La llegada al poder del regente Horthy marcó el comienzo de una dura política nacional hacia las minorías nacionales. En 1923 se aprobó un decreto oficial sobre los derechos de las minorías, en virtud del cual se garantizaba a las minorías el derecho a la enseñanza en su lengua materna y a la creación de clases paralelas. De hecho, el nuevo sistema escolar para las minorías se ha aplicado solo parcialmente o se ha encontrado con la resistencia de las autoridades locales ${ }^{74}$.

Para aplicar las disposiciones del tratado de paz de Saint-Germain de 10 de septiembre de 1919, en 1937 se aprobó en Burgenland la Ley de escuelas, que otorga a los húngaros y croatas el derecho a estudiar en su lengua materna en municipios con una proporción minoritaria superior al 70\%. En los municipios con una proporción minoritaria relevante: entre el $30 \%$ y el $70 \%$, las escuelas bilingües se institucionalizaron; menos del $30 \%$, el idioma minoritario se enseñó como materia optativa ${ }^{75}$.

A diferencia de Burgenland, en Carintia las autoridades siguieron una política nacionalista alemana. En particular, la germanización se llevó a cabo en escuelas bilingües, escuelas eslovenas que luego se cerraron. Los maestros eslovenos fueron trasladados de regiones étnicamente mixtas a áreas pobladas puramente alemanas, los niños que estudiaban en escuelas eslovenas se comprometieron a asistir a escuelas bilingües. Se han eliminado los signos topográficos bilingües. Debido a la represión política y social, los eslovenos de Carintia se negaron a registrarse por nacionalidad, por lo que el Gobierno no aprobó ninguna disposición especial para mejorar la enseñanza de la lengua materna a los eslovenos en Carintia ${ }^{76}$. En consecuencia, en el territorio de la primera República de Austria, las autoridades siguieron una política lingüística multidireccional, es decir, asimilación y pluralismo.

En Polonia, en 1924, se aprobó la Ley sobre la creación de escuelas bilingües («utraquistas») en Bielorrusia occidental y Ucrania occidental («Kresovskaya Act»), que

72 The Federal Constitutional law of Austria, 1920. [Electronic resource]. Access mode: http://constitutionnet.org/sites/default/files/Austria\%20_FULL_\%20Constitution.pdf (Date accessed: 03.05.2019).

${ }^{73}$ KUPPER, H., Das neue Minderheitenrecht in Ungarn. Südostinstitut Oldenbourg, München 1998.-P.78.

${ }^{74}$ KUPPER, H. Das neue Minderheitenrecht in Ungarn. Südostinstitut Oldenbourg, München 1998.-P.78.

75 Burgenländisches Landesschulgesetzes 1937 über die Regelung desVolksschulwesens im Burgenland [Regional School Act of Burgenland 1937 on the Regulation of the Primary School System inBurgenland]. LGB1. Nr. 40/1937.

${ }^{76}$ Practice of Minority Protection in Central Europe: Austria. [Electronic resource]. Access mode: https://www.amazon.co.uk/Practice-Minority-Protection-Schriftenreihe-Europaischen/dp/3832960252 (Date accessed: 06.05.2019). 
permitió a las autoridades locales mantener la documentación en dos idiomas, a los ciudadanos utilizar su lengua materna en las instancias estatales y a las escuelas introducir la enseñanza de los idiomas ucraniano y Bielorruso en la escuela. Más tarde, el idioma ucraniano comenzó a ser atacado, las universidades y escuelas ucranianas se cerraron regularmente. En 1929, solo cuatro escuelas secundarias enseñaban el idioma ucraniano. Políticamente, el gobierno polaco ha intentado que los polacos étnicos sean elegidos desproporcionadamente en todos los órganos de gobierno. Los ucranianos reaccionaron con una fuerte oposición. En la década de 1930, el país se inclinó cada vez más hacia el autoritarismo presidencial. El autogobierno garantizado a los ucranianos por el tratado de Versalles se hizo cada vez más limitado. Parte de esta disminución en el autoritarismo fue una mayor represión contra los ucranianos. Las autoridades polacas llevaron a cabo medidas similares («Prussanización») contra las minorías alemanas en La alta Silesia, en defensa de las cuales Alemania recurrió a la liga de las Naciones y a la Cámara Permanente de justicia internacional. Las políticas adoptadas por el gobierno Polaco en los años de entreguerras se centraron en la asimilación cultural y lingüística violenta, alimentando el resentimiento entre las minorías lingüísticas y los polacos, que años después, en la segunda mitad de la segunda guerra mundial, se convirtió en un conflicto abierto $^{77}$.

A lo largo de la existencia de la República de Weimar (1918-1938), el Gobierno siguió una política de doble filo, presentándose como defensor legítimo de los derechos de las minorías y tratando de dejar abierta la puerta al retorno del territorio y la influencia en la parte de Europa Oriental que se había perdido como resultado de la guerra. Sin embargo, distinguió diligentemente entre el comportamiento bastante conciliador de la política exterior hacia las potencias victoriosas de Inglaterra y Francia y las políticas más violentas dirigidas a los países a lo largo de la frontera Oriental de Alemania ${ }^{78}$. Como sostiene Fink, la política exterior de Weimar estaba dirigida a implementar cambios "evolutivos" y la política hacia las minorías no estaba motivada por objetivos expansionistas, sino más bien políticos, contra los grupos nacionalistas anti - Weimar dentro de Alemania ${ }^{79}$. Kurt D. señala el imperialismo cultural existente (la imposición de la lengua y la cultura alemanas, el abuso de ellos en la política exterior ${ }^{80}$ en la República de Weimar, que condujo al régimen del nazismo.

El 30 de enero de 1933, A. Hitler, presidente del partido obrero alemán Nacionalsocialista, fue nombrado canciller del Reich. En 1938, como resultado de la ocupación Nazi de la primera República de Austria, los maestros, sacerdotes y funcionarios eslovenos y croatas fueron transferidos a territorios de habla alemana. El Esloveno y el Croata fueron prohibidos como idioma de enseñanza. En las escuelas bilingües de Carintia comenzaron a utilizarse los libros de texto alemanes. En 1942, los

77 Between Hitler and Stalin. [Electronic resource]. Access mode: http://www.ucrdc.org/HIPOLONIZATION.html(Date accessed: 04.05.2019).

${ }^{78}$ ULF, T. Weimar Germany's foreign policy and the protection of minorities: The case of the German minority in Poland. Historia Caribe - Volumen IX N 25 - Julio-Diciembre, 2014. -P.45.

${ }^{79}$ SCHOT, B. Nation oder Staat. -P.40.

${ }^{80}$ KARNAUHOVA, E. E. Izmenenie strategii vneshney kulturnoy i yazyikovoy politiki Germanii na sovremennom etape// Vestnik Nizhegorodskogo universiteta im. N.I.Lobachevskogo, 2012b.-№1(2). P.374. 
eslovenos de Carintia lanzaron una resistencia partidista al régimen nazi para la liberación de Carintia con más de 1.000 eslovenos víctimas de combates y ley marcial ${ }^{81}$.

Por lo tanto, se concertaron tratados de paz con los países derrotados y recién formados después de la primera guerra mundial, que contenían disposiciones para proteger a las minorías. Estas disposiciones se reflejan en las constituciones y leyes de los países. En la práctica, no tenían sentido ni se aplicaban debido a la política de asimilación de las minorías lingüísticas.

La política lingüística en los países ganadores fue heterogénea. Como destaca $\mathrm{H}$. Walter en Francia, el ejército, agrupado por reclutas locales, originalmente se comunicaba en sus idiomas regionales. En la guerra, el francés se convirtió en el idioma de comunicación y, a su regreso a casa, los soldados continuaron comunicándose en francés y enseñándole a sus hijos ${ }^{82}$. En este período se forman movimientos autonomistas y regionales de grupos de activistas políticos. R. A. Lodge sugiere que las personas renuncian a uno de sus idiomas durante sus vidas solo si una generación transmite solo uno de sus idiomas a la siguiente ${ }^{83}$. Se puede suponer que la Primera guerra mundial fue el catalizador de un cambio de lenguaje significativo entre los descendientes de los participantes de la primera guerra mundial.

En Italia, después de la anexión del Tirol del sur (octubre 10, 1920), comenzó una política de «barrer» a los alemanes. Como resultado, las escuelas locales alemanas se cerraron, las localidades, los nombres y apellidos de los alemanes se italianizaron y se prohibió la enseñanza del alemán ${ }^{84}$. En 1922, bajo el liderazgo de B. Mussolini, comenzó «la desnacionalización de las minorías nacionales». La política fascista se opuso firmemente al uso de lenguas minoritarias (por ejemplo, Franco - provenzal en valle de Aosta, ladino y alemán en Trentino alto Adige), así como palabras extranjeras (por ejemplo, café, cóctel). Por ejemplo, en 1923, la Liga Waldoten presentó una petición solicitando la autonomía de B. Mussolini, quien en respuesta introdujo una brutal represión y estaba decidido a destruir a los franceses y Franco - provenzales en la región. El francés ha sido prohibido en las escuelas, los tribunales, la administración y la vida pública. Los periódicos locales «el Ducado de Aosta»(Le Duché D'Aoste), «el País de Aosta»(le Pays D'Aost), «La patria valdôtaine» (la Patrie valdôtaine) fueron cerrados ${ }^{85}$.

En Italia, el Estado «solo aceptaba a una persona en la medida en que sus intereses coincidían con los del Estado» ${ }^{86}$. Las personas que no hablaban italiano eran personas que no compartían los intereses del Estado. Las lenguas y dialectos minoritarios se vieron amenazados de una manera que «representaba todo lo que incluía regionalismo político,

\footnotetext{
${ }^{81}$ Practice of Minority Protection in Central Europe: Austria. [Electronic resource]. Access mode: https://www.amazon.co.uk/Practice-Minority-Protection-Schriftenreihe-Europaischen/dp/3832960252 (Date accessed: 06.05.2019).

${ }^{82}$ WALTER, H. Le Français dans tous les sens, Paris, Robert Laffont, 1988.-P.126.

${ }^{83}$ LODGE, R. A. French: From Dialect to Standard, London, Routledge,1993.-P.192.

${ }^{84}$ ULRIH, V. Os Berlin-Rim. Soyuz Mussolini i Gitlera. [Electronic resource]. Access mode: http://www.brusselstimes.com/magazine2/12050/the-flemish-movement-how-language-shapedbelgium(Date accessed: 09.01.2018).

${ }^{85}$ Italy: Aostans. [Electronic resource]. Access mode: https://minorityrights.org/minorities/aostans/ ( Date accessed:10.01.2019).

${ }^{86}$ CAVANAUGH, J. R. A Modern Questione della Lingua: The Incomplete Standardization of Italian in a Northern Italian Town. The Journal of the Society for the Anthropology of Europe 8, no. 1 (Spring/Sumer, 2008). -P.22.
} 
desunión cultural y anti-modernismo». Como escribe T. P. Nesterova, una de las principales tareas estatales fue la difusión de un solo idioma nacional italiano en grandes masas ${ }^{87}$. Se introdujo un nuevo método de enseñanza «del dialecto al idioma» (dal dialetta alla lingua) para el aprendizaje exitoso del italiano en las escuelas ${ }^{88}$. En 1923 se aprobó un Decreto de octubre en el que se reconocía al italiano como el único idioma las lenguas minoritarias y los dialectos del proceso de enseñanza en las escuelas fueron excluidos. Las autoridades regionales se comprometieron a hacer cumplir esas restricciones cerrando o confiscando la publicación pertinente en idiomas minoritarios (por ejemplo, manuales escolares). Para mejorar la alfabetización de la población. Mussolini introdujo la educación escolar gratuita en italiano literario. Los programas de radio y televisión se transmitían en italiano. En 1939, en el valle de Aosta, los nombres geográficos fueron cambiados del francés al italiano. Sin embargo, los planes para cambiar los 20.000 apellidos no se llevaron a cabo debido al estallido de la segunda guerra mundial ${ }^{89}$.

En el territorio de Irlanda del Norte en el período de entreguerras de este tiempo, comenzó la confrontación de dos comunidades del Ulster: la católica, que buscaba la reunificación con gran Irlanda, y la protestante, que quería permanecer en el Reino Unido de gran Bretaña e Irlanda del Norte ${ }^{90}$. Desde la década de 1920, la represión directa comenzó en Irlanda del Norte, a partir de la década de 1930, el irlandés fue visto a regañadientes como una lengua extranjera en el sistema educativo, pero, a diferencia de otros idiomas, fue abusado periódicamente por los políticos unionistas ${ }^{91}$. En una entrevista con noticias irlandesas nacionalistas, D. Shannon, un miembro del Consejo sindical, llamó al irlandés (gaélico) «un lenguaje muerto para el pueblo muerto» ${ }^{92}$. La política de los uniostes tenía como objetivo desplazar el idioma irlandés.

Los movimientos y partidos nacionales continuaron trabajando en otras partes del Reino Unido. En Gales, por ejemplo, en 1939, la Unión de sociedades galesas presentó una petición para el reconocimiento del idioma galés en los tribunales, firmada por más de 250, 000 personas y respaldada por 30 de los 36 diputados galeses ${ }^{93}$.En 1942, se aprobó la Ley de tribunales galeses de 1942, según la cual los galeses tenían derecho a usar el idioma galés en los tribunales, se permitió la traducción de la documentación judicial al galés. Además, la ley permitía la celebración de juicios con intérpretes cuando fuera necesario. Además, la ley aclaró que "nada de lo dispuesto en esta Ley perjudicará el uso

\footnotetext{
${ }^{87}$ NESTEROVA, T.P. Ot reformyi Dzhentile k reforme Bottai: obrazovatelnaya politika Italii v 19201930-h gg. [Tekst] / T.P.Nesterova //Izv. Uralskogo gos. universiteta. - 2008. - № 59. - P. 118-126.

${ }^{88}$ Language planning and policy in europe. the Baltic states, ireland and italy [Text] // language planning and policy in europe / ed. by robert B. Kaplan and richard B. Baldauf. - multilingual matters ltd., 2008. v. 3. -P.303.

${ }^{89}$ Italy: Aostans. [Electronic resource]. Access mode: https://minorityrights.org/minorities/aostans/ (Date accessed:10.01.2019).

90 Sayt obschestvenno-politicheskogo zhurnala Planeta// URL: https://planeta.by/article/687 (Date accessed:22.04.2019).

${ }^{91}$ ANDREWS, «The Very Dogs in Belfast». -P.87.

92 Committee on the Administration of Justice, Staid agus stádas na Gaeilge i dtuais- ceart na hÉireann. P.29.

${ }^{93}$ GOODEN, J. The law and the Welsh language. [Electronic resource]. Access mode: https://www.bbc.co.uk/blogs/wales/entries/020f5be9-73a7-3491-a4dd-57fc6875eade (Date
} accessed:22.04.2019). 
del idioma galés en todos los casos en que sea legal" (Art.5) ${ }^{94}$. Las actividades de la Unión de sociedades galesas dieron los primeros resultados positivos.

La política lingüística de la posguerra de Bélgica continuó desarrollándose en la dirección del pluralismo. Como resultado de la primera guerra mundial, Bélgica anexó los cantones orientales de habla alemana. En 1921 se implementó el principio territorial. La mayoría de los habitantes de una comunidad han comenzado a definir el área lingüística (holandesa o francesa) con un recuento cada 10 años. En 1930, se introdujo la enseñanza en Holandés en la Universidad Católica de Lovaina.

En la década de 1930, el Gobierno belga aprobó las siguientes leyes lingüísticas:

1.Ley de 28 de junio de 1932 sobre el uso de idiomas en asuntos administrativos ${ }^{95}$. La ley establecía que los servicios públicos locales y provinciales y sus órganos administrativos y públicos subordinados, así como las comunas y sus órganos administrativos y públicos subordinados, redactarían anuncios e información pública en el idioma de las unidades territoriales inferiores (comunas) de Bélgica. Por ley de 8 de noviembre de 1962 se enmendó para ampliar la lista de comunas y aprobar los dos idiomas nacionales en los idiomas de los anuncios y notificaciones ${ }^{96}$.

2.Ley de 14 de julio de 1932 sobre el uso de idiomas en la educación primaria y secundaria. La ley dividió las instituciones educativas en monolingües y bilingües. En las partes monolinguies del país (región Flamenca, región Valona y comunidades de habla alemana), la enseñanza se impartía en el idioma de la región (artículos 1, 8 y 14 de la Ley). De conformidad con los artículos 6, 13, la enseñanza de la segunda lengua nacional era obligatoria en las comunidades ubicadas dentro del territorio urbano de Bruselas, así como en las comunidades bilingües en la frontera entre las ciudades. La sección 3 (1) también introdujo un censo de población cada diez años para detectar cambios en la comuna belga con respecto a las lenguas. Los resultados de estos censos podrían haber dado lugar a cambios en la legislación aplicada en estas comunidades, tanto en el ámbito educativo como administrativo ${ }^{97}$.

3.Ley de 15 de junio de 1935 sobre la aplicación de la lengua en los asuntos judiciales ${ }^{98}$. El punto de partida de la ley era el uso de uno o más idiomas (francés, holandés o alemán) durante todo el proceso. Los juicios civiles se llevaron a cabo en el idioma de presentación de la demanda, a menos que el demandado solicitara un juicio en otro idioma. Sin embargo, el juez podría negarse a aceptar la solicitud si en el caso había

\footnotetext{
94 Welsh Courts Act, (1942). [Electronic resource]. Access mode: http://www.legislation.gov.uk/ukpga/Geo6/5- 6/40/enacted (Date accessed: 09.04.2019).

95 Judgment of the European Court of Human Rights of case «Relating to certain aspects of the laws on the use of languages in education in Belgium»v. Belgium (Merits). [Electronic resource]. Access mode; https://minorityrights.org/wp-content/uploads/old-site-downloads/download-223-Belgian-Linguistic-casefull-case.pdf(Date accessed:11.11.2018).

96 Language facilities in the Brussels Periphery.Evolution, areas of conflict and linguistic practices [Electronic resource]. Access mode: http://www.briobrussel.be/assets/brusselse\%20themas/bt9summary.pdf(Date accessed:16.11.2018).

${ }^{97}$ European Convention on Human Rights Year: 1974.Council of Europe/Conseil de L'Europe Martinus Nijhoff Publishers, 1st of March, 1976 г. - P.560.

${ }^{98}$ Loi de 15 juin 1935 concernant l'emploi des langues en matière judiciaire [Act concerning the use of languages in judicial matters] of June 15,1935, «Moniteur Belge» [«M.B.»], 1935.06.22, [Electronic resource]. Access mode: http://www.axl.cefan.ulaval.ca/europe/belgiqueetat-loi1935.htm(Date accessed:15.10.2018).
} 
pruebas de que el demandado dominaba el idioma del procedimiento en el nivel necesario. La apelación y los argumentos a favor de la apelación debían presentarse en el idioma de la decisión impugnada. El juicio en la máxima instancia judicial se llevó a cabo en el idioma de la decisión impugnada. Si los documentos se proporcionaban en un idioma distinto del procedimiento, el tribunal, a petición de la parte a la que se hacía referencia en los documentos, podía dictar una orden motivada para traducir el documento al idioma del procedimiento. En áreas bilingües, se permitió el uso de ambos idiomas ${ }^{99}$.A petición del demandado, las actuaciones (iniciadas en francés u holandés) podrían continuar en otro idioma (Sección 4 párrafo 1 de la Ley sobre el uso del lenguaje en los asuntos judiciales de 1935). Los acusados que residían en municipios pertenecientes a las zonas fronterizas lingüísticas tenían derecho a solicitar un juicio en francés (Sección 7 párrafo 1 de la Ley sobre el uso del lenguaje en los asuntos judiciales de 1935). Las partes tenían derecho a solicitar un cambio en el idioma de los procedimientos. Dependiendo del idioma establecido por la ley, el tribunal podría continuar el procedimiento en otro idioma o llevarlo a otro tribunal. Como resultado, estas leyes actuaron de acuerdo con el nuevo principio de «idioma del territorio - idioma de la educación» ${ }^{100}$ y contribuyeron al surgimiento del bilingüismo asimétrico. Como parte de la aplicación de estas leyes, se han establecido instituciones bilinguies en Bruselas en las zonas donde viven las minorías lingüísticas. La región Flamenca se convirtió en bilingüe, mientras que el resto de Bélgica permaneció monolingüe ${ }^{101}$.Posteriormente, la Segunda guerra mundial profundizó la división entre las dos comunidades lingüísticas ${ }^{102}$.

Por lo tanto, en el período posterior a la Primera guerra mundial y antes del estallido de la Segunda guerra mundial, la política lingüística en la mayoría de los países europeos fue principalmente asimilar. En la conferencia de paz de París, los países ganadores de la primera guerra mundial prepararon y acordaron una serie de tratados con minorías y decidieron crear la sociedad de Naciones como foro para la solución pacífica de posibles controversias futuras. Los tratados de paz que protegen a las minorías constituyen una innovación absoluta en la política mundial ${ }^{103}$ y sus disposiciones se han incorporado a las constituciones y leyes de muchos países. Sin embargo, en lugar de poner en práctica esta situación, los países derrotados (excepción, Burgenland en la primera República de Austria) adoptaron políticas destinadas a erradicar y expulsar las lenguas regionales y minoritarias. Sin embargo, Bélgica es el único país en cuestión en el que las políticas públicas se han centrado en el bilingüismo y la mejora de la legislación lingüística. La

\footnotetext{
${ }^{99}$ BAMBUST I., KRUGER A., KRUGER T. Constitutional and judicial language protection in multilingual states: A brief overview of South Africa and Belgium. [Electronic resource]. Access mode: https://core.ac.uk/download/pdf/43326647.pdf (Date accessed: 11.11.2018).

100 BEHEYDT, L., The Linguistic Situation in a New Belgium, in in languages in contact and conflict, contrasting experiences in the Netherlands and Belgium //Sue Wright ed., Multilingual Matters Ltd. 1995. -P.48,52.

${ }^{101}$ HOOGHE, L., Belgium: Hollowing the Center, in federalism. unitarism, and territorial cleavages (Ugo Amoretti, Nancy Bermeo eds., Johns Hopkins Press 2002). [Electronic resource]. Access mode: http://www.unc.edu/ hooghe/assets/docs/books/princeton_finaldraft.pdf (Date accessed:14.10.2018).

${ }^{102}$ The Flemish Movement: How language shaped Belgium. [Electronic resource]. Access mode: http://www.brusselstimes.com/magazine2/12050/the-flemish-movement-how-language-shapedbelgium(Date accessed:09.01.2018).

${ }^{103}$ FINK, C., «Stresemann’s Minority Policies, 1924-29», Journal of Contemporary History 14: 3, 1979. P.404.
} 
labor de algunos movimientos y partidos nacionales en Gales ha dado lugar a la adopción de nuevas leyes que consagran la condición de lenguas minoritarias.

\section{Quinto período (1945 a 1989)}

El genocidio y la persecución contra las minorías nacionales cometidos por los nazis en los territorios ocupados por Alemania y en los países aliados de Hitler durante la Segunda guerra mundial causaron la muerte masiva de las minorías y la pérdida de su cultura. El final de la segunda guerra mundial marcó la liberación de los países del régimen fascista, la creación de nuevos Estados, la celebración de conferencias de posguerra para concluir tratados de paz con los países de la coalición de Hitler, el establecimiento de las Naciones Unidas y la adopción de normas internacionales para la protección de los derechos humanos.

El período que se examina se caracteriza por la intensa actividad legislativa de los Estados en la esfera de la protección de los derechos lingüísticos de las minorías, a saber:

1. Modificación de las leyes básicas de los Estados. Sobre la base del análisis de las constituciones aprobadas después de la Segunda guerra mundial, se pueden distinguir las siguientes especies:

1.1 constituciones que contienen disposiciones para la protección de las minorías. El artículo 6 de la Constitución italiana, de $1^{\circ}$ de enero de 1948, proclama que «la República garantiza la protección de las minorías lingüísticas mediante medidas apropiadas». En el artículo 3 se afirma que «todos los ciudadanos tienen la misma dignidad social y son iguales ante la ley, sin distinción de sexo, raza, idioma, religión, opinión política, situación personal y social. La República tiene el deber de eliminar los obstáculos al orden económico y social que limitan la libertad y la igualdad de los ciudadanos, impidiendo así el pleno desarrollo de la persona humana y la participación efectiva de todos los trabajadores en la organización política, económica y social del país ${ }^{104} \gg$. Esto significa que las políticas relativas a las minorías se han centrado en la protección positiva. En las regiones autónomas de Trentino-alto Adige, especialmente en las provincias de Bolzano, Bozen, Tirol del sur y Val D'Aosta, fue posible asistir a escuelas de habla francesa y alemana, cuyos idiomas se hicieron oficiales en la zona. En Trieste y Gorizia aparecieron escuelas en esloveno.

En 1949 se aprobó la Constitución de la República de Hungría, en cuyo párrafo 2 del artículo 68 se proclama «la protección de las minorías nacionales y étnicas, su participación colectiva en los asuntos públicos, el desarrollo de su cultura, el uso de sus lenguas maternas, la educación en sus lenguas maternas y el uso de nombres en sus lenguas maternas ${ }^{105} \gg$. Solo los alemanes, los eslovacos y los «eslavos del sur» (croatas, serbios y eslovenos) eran reconocidos como minorías étnicas, mientras que los judíos eran

\footnotetext{
${ }^{104}$ The Constitution of the Italian Republic 1948. [Electronic resource]. Access mode: https://www.senato.it/documenti/repository/istituzione/costituzione_inglese.pdf(Date accessed:11.01.2018).

${ }^{105}$ The Constitution of the Republic of Hungary, Act XX of 1949. [Electronic resource]. Access mode: https://www2.ohchr.org/english/bodies/cescr/docs/E.C.12.HUN.3-Annex2.pdf accessed:07.05.2019).
} 
considerados una minoría religiosa ${ }^{106}$. En 1972, los derechos de las minorías nacionales se ampliaron mediante una enmienda constitucional que garantizaba a las minorías más derechos educativos y culturales. En los años siguientes, se concedió a las minorías étnicas el derecho a registrar sus nombres en los documentos oficiales y a colocar carteles con los nombres de las calles o edificios públicos en los idiomas de las minorías ${ }^{107}$.

El artículo 8 de la Constitución de Austria de 1920 (enmendada en 1945) ${ }^{108}$ pide el respeto, la protección y el apoyo de la lengua y la cultura, la existencia y la conservación de los grupos étnicos. La República (Federación, Lenders y municipios) apoya la creciente diversidad lingüística y cultural expresada en grupos étnicos autóctonos.

La Constitución francesa de 1958 reconoce el francés como idioma oficial del país (Art .2) y los idiomas regionales como parte del Patrimonio de Francia (Art. 75-1) ${ }^{109}$.

1.2. Constituciones que no contienen disposiciones sobre la protección de las minorías. La Constitución de Polonia de 1952 incluía las garantías generales de «igualdad de todos los ciudadanos» (artículo 67) y las reglas de no discriminación (artículo 81) ${ }^{110}$. El documento garantizaba el principio general de no discriminación como principio fundamental de la protección de los ciudadanos, que incluía a los ciudadanos pertenecientes a minorías y constituía una clara ruptura con las disposiciones de la Constitución anterior a la guerra. La Constitución Alemana de 1949 garantiza la igualdad de derechos en todas las esferas de la vida pública, política, económica, social y cultural, independientemente del sexo, el origen, la raza, el idioma, la patria y el origen, la fe o las creencias religiosas o políticas, y la discapacidad (Art.3) ${ }^{111}$.

2. Aprobación de reglamentos que afectan a la educación y a los medios de comunicación:

Con el fin de proteger los idiomas oficiales (francés) y regionales en Francia, el 11 de enero de 1951, se aprobó la Ley M. Dexon. Según esta ley, el euskera, el catalán, el bretón y el occitano han sido reconocidos como lenguas regionales (art.10). En el programa de educación pública se ha introducido una clase opcional de una hora en cuatro idiomas una vez a la semana (art.3). En el marco de las disposiciones relativas a la educación general, los idiomas se consideraron como asignaturas complementarias opcionales y se tuvieron en cuenta sólo en un pequeño grado (art. 8). En las escuelas generales, los liceos y los colegios se han impartido cursos optativos a los alumnos que

\footnotetext{
${ }^{106}$ BRIGITTE, M., Vergleichende Studien zur Situation der Minderheiten in Ungarn und Rumänien (19891996) unter besonderer Berücksichtigung der Roma (Peter Lang, Frankfurt et.al., 1999.-P. 52.

107 BAKKER, E., Minority Conflicts in Slovakia and Hungary? (Labyrint Publication, Ijssel 1997), note $14,151 f$.

${ }^{108}$ The Constitution of the Republic of Austria 1920. [Electronic resource]. Access mode: https://www.constituteproject.org/constitution/Austria_2013.pdf?lang=en (Date accessed:20.05.2019).

${ }^{109}$ The Constitution of the Republic of France 1958. [Electronic resource]. Access mode: https://www.conseilconstitutionnel.fr/sites/default/files/as/root/bank_mm/anglais/constiution_anglais_oct 2009.pdf (Date accessed:20.05.2019).

${ }^{110}$ The Constitution of the Republic of Poland 1952. [Electronic resource]. Access mode: http://libr.sejm.gov.pl/tek01/txt/kpol/e1952a-r7.html (Date accessed:20.05.2019).

111 Basic Law for the Federal Republic of Germany 1949. [Electronic resource]. Access mode: https://www.btg-bestellservice.de/pdf/80201000.pdf (Date accessed:07.05.2019).
} 
tengan la intención de enseñar en los distritos (Art.5,6) ${ }^{112}$.Según D. Ajer, esta ley puso fin a «un siglo y medio de ataques sistemáticos contra el uso de idiomas regionales» ${ }^{113} \mathrm{y}$ es importante en la medida en que se convirtió en el reconocimiento oficial del derecho a la existencia de idiomas regionales por primera vez.

Gracias a la Ley Xabi de 11 de julio de 1975, los estudiantes de las escuelas tuvieron la oportunidad de aprender idiomas y culturas regionales (art.12) ${ }^{114}$. El programa incluyó una sesión obligatoria (tres horas al año) sobre la comparación de los idiomas francés y regional, y una sesión sobre historia y aprendizaje de diez textos regionales sobre civilización (10 horas al año) durante todo el período de estudio ${ }^{115}$.

La innovación es el programa de enseñanza de lenguas y culturas regionales, publicado en la carta Informativa № 82-261, de 12 de junio de 1982, según la cual:

- el Estado debe ser responsable de la enseñanza de las lenguas regionales;

- los idiomas regionales deben tener el estatus de una disciplina separada y enseñarse desde el nivel de entrada hasta la Universidad;

- la enseñanza de idiomas regionales debe basarse en el deseo expresado de los maestros y estudiantes ${ }^{116}$.

En 1963, Bélgica comenzó una segunda ola de reformas legislativas, en el marco de la cual se aprobó una Ley el 30 de julio de 1963 sobre la regulación del uso de idiomas en el sistema educativo. El artículo 4 de la ley establece cuatro idiomas de enseñanza: el Holandés en la región de habla holandesa, el francés en la región de habla francesa y el alemán en la región de habla alemana ${ }^{117}$. La enseñanza preescolar y primaria puede impartirse en otro idioma nacional bajo las siguientes condiciones:

- este idioma es el idioma nativo o normal del niño;

- el jefe de la familia reside en uno de los distritos pertinentes;

- un número suficiente de jefes de familia lo piden.

En el área Metropolitana de Bruselas, el jefe de familia puede elegir qué idioma enseñar al niño: francés u holandés. El derecho a la enseñanza en la lengua materna se basa en la solicitud de los padres, que es verificada por una inspección lingüística especial $^{118}$.

${ }^{112}$ La loi no 51-46 du 11 janvier 1951 relative à l'enseignement des langues et des dialectes locaux. [Electronic resource]. Access mode: http://www.axl.cefan.ulaval.ca/europe/France-loi_Deixonne-texte1951.htm(Date accessed:11.02.2019).

113 AGER, D. (1999) Identity Insecurity and Image: France and Language. -1999. -P.31.

${ }^{114}$ Loi № 75-620 du 11 juillet 1975 relative à l’éducation «Loi Haby», version consolidée au 21 juin 2000. [Electronic resource]. Access mode: http://www.observatori-occitan.org/documents/1975_Loi_Haby.pdf (Date accessed:11.02.2019).

$115 \mathrm{Id}$.

${ }^{116}$ SORCHA, F., Reversing Language Shift in France: The Breton Case. [Electronic resource]. Access mode:https://www.scss.tcd.ie/undergraduate/computer-science-language/bacsll_web/foy0102.pdf (Date accessed:11.02.2018).

${ }^{117}$ Belgium Linguistics Case - «In the case "relating to certain aspects of the laws on the use of languages in education in Belgium» v Belgium (Application no 1474/62; 1677/62; 1691/62; 1769/63; 1994/63; 2126/64). [Electronic resource].

Access mode:http://www.equalrightstrust.org/ertdocumentbank/Microsoft $\% 20$ Word\%20$\%$ 20Belgian\%20linguistics\%20case.pdf ${ }^{117}$ (Date accessed:26.11.2018).

118 MCRAE, K.D. Conflict and Compromise in Multilingual Societies. (Belgium) (Waterloo: Wilfred Laurier Press, 1986). -P.221. 
En Italia, se aprobaron estatutos especiales a nivel regional. En particular, el artículo 38 del estatuto especial del valle de Aosta, de 26 de febrero de 1946, proclamó la igualdad de trato entre el francés y el italiano. En las escuelas de todos los niveles, se asignaba a ambos idiomas el mismo número de horas semanales (art.40). Se garantizó a la población de habla alemana de los municipios del Valle-del-Lis la enseñanza del alemán en las escuelas, así como el derecho a la protección de sus características y tradiciones lingüísticas y culturales (art.40) ${ }^{119}$. La región Autónoma de Trentino-Alto Adige contaba con un Estatuto Especial de 26 de febrero de $1946^{120}$, cuya sección X se refiere al uso de los idiomas alemán y ladino. A pesar de que el idioma oficial es el italiano, los idiomas anteriores se pueden utilizar en las relaciones con la administración pública y en el campo de la educación. Las actividades de la región Autónoma de Friuli-Venecia Julia se rigen por un estatuto Especial de 31 de enero de 1963, que proclama el derecho de todos los ciudadanos a la igualdad de derechos y trato, independientemente del grupo lingüístico al que pertenezcan, manteniendo sus respectivas características étnicas y culturales $(\operatorname{art} .3)^{121}$.

Los derechos de los ciudadanos de las minorías eslovena y Croata en Carintia, Burgenland y Estiria están consagrados en el artículo 7 de la ley estatal de Viena de 1955. Estos ciudadanos tienen derecho a la enseñanza primaria en esloveno o croata y a un número proporcional de sus propias escuelas secundarias. A este respecto, se están revisando los programas escolares y se está estableciendo una inspección educativa para las escuelas eslovenas y croatas $^{122}$. De conformidad con el párrafo 2 del artículo 10 de la ley Federal sobre la enseñanza de las minorías en la provincia de Carintia, de $1959^{123}$, se garantizó a las minorías eslovenas el establecimiento de escuelas nacionales y secundarias en las comunidades en las que la enseñanza en las escuelas populares y secundarias se impartió en dos idiomas al comienzo del año escolar 1958/59. Las formas comunes de enseñanza primaria y secundaria con alemán incluían los siguientes tipos de escuelas:

a) escuelas primarias y secundarias con idioma esloveno;

b) escuelas primarias, clases o departamentos con enseñanza de alemán y esloveno (escuelas primarias bilingües, clases o departamentos);

\footnotetext{
${ }^{119}$ Statuto speciale per la Valle d'Aosta, Legge costituzionale 26 febbraio 1948. [Electronic resource]. Access

mode:http://www.regione.fvg.it/rafvg/export/sites/default/RAFVG/GEN/statuto/allegati/statutoGiugno20 03.pdf (Date accessed: 18.05.2019).

${ }^{120}$ Statuto speciale per il Trentino-Alto Adige, Legge costituzionale 26 febbraio 1948. [Electronic resource]. Access mode:http://www.consiglio-bz.org/download/1.Statuto-di-Autonomia-1948.pdf (Date accessed: 18.05.2019).

${ }^{121}$ Statuto Speciale della regione autonomia Friuli n Venezia Giulia, Legge costituzionale 31 gennaio 1963, n. 1 e successive modifiche ed integrazioni. [Electronic resource]. Access mode:http://www.regione.fvg.it/rafvg/export/sites/default/RAFVG/GEN/statuto/allegati/statutoGiugno20 03.pdf (Date accessed: 18.05.2019).

122 State Treaty (with annexes and maps) for the re-establish-ment of an independent and democratic Austria, on 15 May 1955. [Electronic resource]. Access mode:https://www.dipublico.org/100823/statetreaty-with-annexes-and-maps-for-the-re-establish\%C2\%ADment-of-an-independent-and-democraticaustria-signed-at-vienna-on-15-may-1955/ (Date accessed: 20.05.2019).

${ }^{123}$ The Federal Law for minority schooling from 1959 (BGB1. 101/1959). [Electronic resource]. Access mode:https://www.ris.bka.gv.at/Dokumente/BgblPdf/1959_101_0/1959_101_0.pdf accessed:20.05.2019).
} 
c) unidades de enseñanza eslovena establecidas en escuelas secundarias con enseñanza alemana $(\$ 12)$ (enseñanza obligatoria del esloveno: cuatro horas a la semana (§ 16). En las escuelas primarias y secundarias con enseñanza en alemán, la enseñanza del esloveno se introdujo como una asignatura opcional. La ley también preveía que los niños se inscribieran en la enseñanza bilingüe sobre la base de las solicitudes de los padres o tutores legales. Se forma una clase bilingüe separada con al menos nueve alumnos (de un total de al menos 18 niños). La capacitación es impartida por dos profesores: bilingüe y colectivo, si hay menos de nueve personas en una clase ${ }^{124}$.

En Hungría, en 1949, se fundó el nuevo gimnasio eslovaco, de 1952 a 1960, el número de guarderías y escuelas primarias alemanas aumentó de 25 a 164. Debido a la escasez de maestros, así como a los materiales educativos relevantes, las lenguas minoritarias solo se enseñaron como una asignatura adicional en las escuelas. Para mejorar la situación, se introdujo un sistema de educación bilingüie ${ }^{125}$.

En la República Federal de Alemania, en 1955 se firmaron las Declaraciones de Bonn y Copenhague ${ }^{126}$, que garantizaban el establecimiento de escuelas comunes y centros (también especializados) para adultos, así como jardines de infancia para las minorías danesas y alemanas, respectivamente. Los movimientos estudiantiles promovieron la autonomía gradual de las minorías en los campos de la cultura, la educación escolar y la ciencia. El Estado ha adoptado medidas obligatorias para preservar la identidad nacional e introducir señales de tráfico bilingües ${ }^{127}$.

El final de la década de 1970 en el Reino Unido de gran Bretaña e Irlanda del Norte estuvo marcado por una política feroz contra los idiomas regionales o minoritarios. La política del partido Conservador en la década de 1980 fue «progresista e intervencionista y fue la piedra angular de la política lingüística posterior ${ }^{128}$. Gracias a los esfuerzos del partido nacional Escocés, se aprobaron leyes: la Ley de educación de $1980^{129}$ y la Ley de subvenciones para la enseñanza del gaélico de $1986^{130}$. En la primera Ley, el gaélico no se consideraba un medio de enseñanza, pero la disposición de la Ley de educación de

\footnotetext{
${ }^{124}$ The Federal Law for minority schooling from 1959 (BGB1. 101/1959). [Electronic resource]. Access mode: https://www.ris.bka.gv.at/Dokumente/BgblPdf/1959_101_0/1959_101_0.pdf (Date accessed:20.05.2019).

${ }^{125}$ BAKKER E., Minority Conflicts in Slovakia and Hungary? //Labyrint Publication, Ijssel 1997. -P. 222. ${ }^{126}$ Bonn-Copenhagen Declarations 1955. [Electronic resource]. Access mode: https://www.ecmi.de/about/history/german-danish-border-region/bonn-copenhagen-declarations/(Date accessed:20.05.2019).

${ }^{127}$ National minorities, minority and regional languages in Germany. [Electronic resource]. Access mode: https://www.bmi.bund.de/SharedDocs/downloads/EN/publikationen/2016/

national-minorities-minority-and-regional-languages-in-germany.pdf?_blob=publicationFile (Date accessed: 20.05.2019).

${ }^{128}$ Welsh Government. (2011). Review of the Welsh Language Support Service for School. [Electronic resource]. Access mode: http:// www.wales.gov.uk/statistics-and-research/re(Date accessed: 22.04.2019).

129 Education (Scotland) Act 1980. [Electronic resource]. Access mode: https://www.legislation.gov.uk/ukpga/1980/44/contents (Welsh Language Support Service for School. [Electronic resource]. Access mode: http:// www.wales.gov.uk/statistics-and-research/re(Date accessed: 21.05.2019).

${ }^{130}$ The Grants for Gaelic Language Education (Scotland) Regulations 1986. [Electronic resource]. Access mode: http://www.legislation.gov.uk/uksi/1986/410/contents/made (Date accessed: 21.05.2019).
} 
1918 para «garantizar adecuadamente» ${ }^{131}$ la enseñanza del gaélico como una asignatura «en áreas en las que se habla gaélico» ha sobrevivido. En 1985 nació la primera escuela primaria con enseñanza en lenguas minoritarias. La segunda ley tenía como objetivo financiar proyectos de enseñanza del idioma gaélico. La ley de reforma educativa de $1988^{132}$ otorgó al galés el estatus de una de las materias principales del plan de estudios nacional en las escuelas secundarias de Gales, definidas como «escuelas de habla galesa». En consecuencia, la educación galesa recibió un reconocimiento completo.

En el ámbito de los medios de comunicación, Gales tiene una Ley de radiodifusión de 1981 que regula la autoridad de las autoridades estatales para administrar su estación regional. En particular, las autoridades estatales de Gales están obligadas a:

- proporcionar programas de televisión (excepto publicidad) de alta calidad al Cuarto canal de Gales organismo de radiodifusión independiente;

- proporcionar a un organismo de radiodifusión independiente el horario de los programas (art. 47) ${ }^{133}$.

La Ley regula claramente el tiempo de emisión de sus propios programas en el Cuarto canal y hace hincapié en que estos programas deben transmitirse en galés ${ }^{134}$. Esta ley permitió a Gales desarrollar un canal nacional de televisión y programas de Radio en galés. Una ley de radiodifusión similar en Escocia de $1990^{135}$ contiene disposiciones sobre el establecimiento de un Comité de televisión gaélico y su responsabilidad de financiar los programas gaélicos.

A diferencia de Gales y Escocia, los activistas del movimiento por el idioma irlandés (gaélico) fueron el foco de la mayoría de los nacionalistas políticamente activos del Norte en el territorio de Irlanda del Norte. Los políticos unionistas difamaron periódicamente el gaélico irlandés. En particular, D. Shannon, miembro del Consejo sindical, llamó a este idioma «un lenguaje muerto para un pueblo muerto». En 1970, varias familias Irlandesas abrieron la primera escuela cuyo idioma de enseñanza era el gaélico irlandés (Bunscoil Phobal Feirste). En 1984, esta escuela recibió el estatus oficial $^{136}$.

3. Aprobación de leyes administrativas y judiciales:

En Bélgica se aprobaron dos leyes sobre el uso de idiomas en los asuntos administrativos, de 2 de agosto de $1963^{137}$ y 18 de julio de $1966^{138}$. El primero consolidó

\footnotetext{
${ }^{131}$ Education Act 1918. [Electronic resource]. Access mode: http://www.legislation.gov.uk/ukpga/Geo5/89/39 (Date accessed: 21.05.2019).

132 Education Reform Act 1988. [Electronic resource]. Access mode: http://www.legislation.gov.uk/ukpga/1988/40/part/II/chapter/I (Date accessed: 21.05.2019).

133 Broadcasting Act. [Electronic resource]. Access mode: http://www.legislation.gov.uk/ ukpga/1981/68/contents (Date accessed: 09.04.2019). ${ }^{134} \mathrm{Id}$.

135 Broadcasting Act (Scotland) 1990. [Electronic resource]. Access mode: http://www.legislation.gov.uk/ukpga/1981/68/contents (Date accessed: 21.05.2019).

${ }^{136}$ School history. [Electronic resource]. Access mode: http://www.bunscoilphobalfeirste.com/Page/School-History/369/Index.html (Date accessed: 21.05.2019).

${ }^{137}$ Loi du 2 août 1963 sur l'emploi des langues en matière administrative. // Moniteur belge du 22 août 1962.

${ }^{138}$ Law Governing the Use of Languages in Administrative Matters. Coordinated on July 18, 1966. [Electronic resource]. Access mode: https://www.uottawa.ca/clmc/kingdom-belgium-law-governing-uselanguages-administrative-matters(Date accessed: 26.11.2018).
} 
el bilingüismo (francés y flamenco (holandés)) en el ámbito de la administración y la educación, así como la frontera dentro de la cual se fijaba la aplicación de los dos idiomas. Los servicios públicos nacionales se han vuelto bilingües. En 25 comunas a lo largo de toda la frontera, se introdujeron regímenes lingüísticos «simplificados» especiales, los llamados «beneficios lingüísticos» ${ }^{139}$. La segunda Ley de Gilson, de 2 de agosto de 1963, estableció un límite lingüístico y dividió a Bélgica en cuatro comunidades linguiísticas: holandesa (Flandes, casi el 60\% de la población), francófona (Valonia, más del 30\%), alemana (menos del 1\%) y holandesa-francesa (bilingüe) ${ }^{140}$. Desde 1966, el cumplimiento de la legislación lingüística en Bélgica fue supervisado por una Comisión especial (vaste Commissie voor Taaltoezicht), que fue nombrada por el rey durante 4 $\operatorname{años}^{141}$.

En Austria, el artículo 2 de la Ley de minorías № 396 de 1976 dispone que las autoridades y los órganos administrativos deben utilizar el idioma de las minorías (párr.12) $^{142}$.

Gracias a los esfuerzos del partido nacionalista galés «Plaid Kimru», la Ley de idioma galés fue aprobada en 1967 en el Parlamento del Reino Unido. A cualquier parte, ya sea un testigo o otra persona, se le permitió utilizar el idioma galés en cualquier juicio en los tribunales de Gales y Monmouthshire, excepto en el tribunal de magistrados (art.1 $)^{143}$.La ley también preveía: la preparación y traducción de documentos al galés, y el uso continuado del galés en la conducción de otros asuntos oficiales o públicos en Gales, en igualdad de condiciones con el inglés. Este fue un importante paso adelante con respecto a la Ley de tribunales galeses de 1942, que condujo a la «igualdad de validez» de ambos idiomas.

4. Creación de organizaciones que representen los intereses civiles y políticos de las minorías nacionales, abogando por su participación en pie de igualdad en la vida política y social, así como por su protección y apoyo como minoría nacional.

Los primeros pasos hacia la liberalización de la política de las minorías fueron la creación de la llamada «Asociación de minorías nacionales» en el marco del frente popular patriótico, en 1948 para los eslovacos y rumanos y en 1955 para los alemanes y las minorías eslavas del sur ${ }^{144}$. En 1984, la Sociedad gaélica de idiomas se estableció en

\footnotetext{
139 DEMESHEVA,Y. V. Konstitutsionno-pravovyie mehanizmyi razresheniya etnolingvisticheskogo konflikta v Belgii: dis. na soi. uchenoy stepeni k. yu. n. [Electronic resource]. Access mode: https://www.hse.ru/data/2015/11/20/1081920950/FIN

AL odt DEMEShEVA POLNYiY TEKST.pdf (Date accessed: 12.11.2018).

${ }^{140}$ HENDRIK, V., Language and Territoriality in Flanders in a historical and international context. [Electronic resource]. Access mode: http://www.flanders.be/en/publications/detail/language-andterritoriality-in- flanders-in-a-historical-and-international-context(Date accessed: 01.10.2018).

141 HENDRIK, V., Language and Territoriality in Flanders in a historical and international context. [Electronic resource]. Access mode: http://www.flanders.be/en/publications/detail/language-andterritoriality-in- flanders-in-a-historical-and-international-context (Date accessed: 01.10.2018).

${ }^{142}$ Bundesgesetz über die Rechtsstellung der Volksgruppen in Österreich (BGB1. № 396/1976. [Electronic resource]. Access mode: https://www.ris.bka.gv.at/Dokumente/BgblPdf/1976_396_0/1976_396_0.pdf (Date accessed: 21.05.2019).

${ }^{143}$ Welsh Language Act, 1967. [Electronic resource]. Access mode: http://www.legislation.gov.uk/ukpga /1967/66/enacted (Date accessed: 06.04.2019).

${ }^{144}$ KUPPER, H. Das neue Minderheitenrecht in Ungarn (Südostinstitut Oldenbourg, München), 1998.P.86.
} 
Escocia para promover el idioma gaélico, la cultura y la coordinación de la política lingüística. En 1988, se estableció en Gales un Consejo de idioma galés para asesorar al secretario de Estado de Gales sobre cuestiones lingüísticas ${ }^{145}$ y se realizaron exámenes. En la República Democrática Alemana comenzó a funcionar el Consejo Central de los sinti y los romaníes alemanes en relación con las minorías sinti y romaníes.

Por lo tanto, las actividades anteriores de los Estados en el período de posguerra se centraron no sólo en el fortalecimiento del marco jurídico y normativo para la protección de las minorías lingüísticas, sino también en el desarrollo de esferas de actividad como la educación, los medios de comunicación y las actividades administrativas y judiciales. Como resultado, se crearon jardines de infancia, escuelas primarias y secundarias, en las que el idioma de enseñanza era el de las minorías nacionales, así como organizaciones especializadas. La peculiaridad de esta etapa es un cambio gradual en el curso de la política lingüística de la asimilación establecida al pluralismo en Austria, Italia, Francia y Alemania. En Bélgica, la segunda ola de reformas legislativas de 1963 reforzó la aplicación de los principios generales establecidos en 1932. La situación es doble en el Reino Unido de gran Bretaña e Irlanda del Norte. Por un lado, desde la década de 1960 en Gales y Escocia se ha hablado de una política de multiculturalismo mediante la introducción de lenguas minoritarias en diversos ámbitos de la vida, la preservación de las tradiciones y costumbres de las minorías locales, por otro lado, en Irlanda del Norte se ha seguido asimilando el idioma irlandés(gaélico). En la agenda de las autoridades comunistas de Polonia y Hungría estaba el fortalecimiento de la heterogeneidad nacional y la promoción de los signos de las actividades de las minorías. Con el colapso del comunismo, los representantes de las minorías nacionales comenzaron a resurgir como una especie de recordatorio de la historia multinacional de Polonia y como una especie de «emblema popular» de los días pasados. En Hungría, la única oportunidad concreta para que las minorías conservaran su identidad nacional independiente era la educación en sus idiomas nativos y las actividades culturales locales, que comenzaron a desarrollarse después de 1949. Las minorías nacionales han comenzado a participar colectivamente en los asuntos públicos, a desarrollar la cultura, a utilizar sus lenguas nativas, a educar en sus lenguas nativas y a utilizar nombres en sus lenguas nativas.

\section{Sexto período (1989 a 2000)}

Esta etapa se caracteriza por el colapso del sistema socialismo, los cambios en el contexto de la situación geopolítica emergente en Europa central y Oriental, y la adopción de los primeros instrumentos a nivel regional sobre los derechos de las minorías.

1. La caída de la cortina de hierro ha llevado a la necesidad de introducir una nueva legislación y, posteriormente, nuevas prácticas en relación con las minorías nacionales y étnicas. El 3 de marzo de 1990 se aprobó una nueva enmienda a la Constitución de 1949. Se añadió al artículo 68 un párrafo 3 que garantizaba la representación de las minorías nacionales y lingüísticas en el Parlamento y en los consejos, independientemente de las elecciones libres y secretas. En relación con esta enmienda, se crearon:

1) Ombudsman de las minorías nacionales y étnicas;

${ }^{145}$ AGER, D. Language policy in Britain and France: the processes of policy. London: Cassell. - 1996. P.168. 
2) Consejo de derechos humanos, cuestiones de las minorías y religión;

3) Oficina de asuntos de las minorías nacionales y étnicas;

4) oficina especial para los romaníes ${ }^{146}$.

Además, en 1993 se aprobó la Ley sobre los derechos de las minorías nacionales y étnicas, que define a las minorías nacionales y étnicas como «aquellos grupos que han vivido en el territorio de la República de Hungría durante al menos cien años son una minoría numerosa en la población del país, son ciudadanos húngaros y difieren del resto de la población por sus idiomas, culturas y tradiciones, al tiempo que muestran un sentido de cohesión para preservar y proteger los intereses de sus comunidades históricas» ${ }^{147}$, también prevé la creación de órganos de gobierno local de las minorías nacionales, establece normas que garantizan la autonomía cultural y el uso de los idiomas de las minorías y regula la asistencia financiera pública a las minorías nacionales y las cuestiones de propiedad.

En Austria, según el censo de 1991, se deduce que la caída de la "cortina de hierro" contribuyó a la sobreestimación del conocimiento de la lengua húngara. El apoyo político a la lengua húngara llevó al reconocimiento de los húngaros que viven en Viena ${ }^{148}$.

2. Cambios territoriales.

Un punto de inflexión en el camino hacia un Estado alemán unificado fue la adhesión de la RDA a la República Federal de Alemania en 1990, lo que llevó a una expansión significativa de los grupos nacionales. El Tratado de unificación entre Alemania y la RDA (Berlín, 31 de agosto de 1990) aclara los derechos linguíísticos del pueblo Lusacia. En particular, el pueblo Lusitano es libre de desarrollar y preservar el idioma Lusitano en la vida pública ${ }^{149}$.

En 1994 se aprobó en Brandeburgo la Ley sobre los derechos de los sorbos/vendas, que promueve y protege el uso de la lengua liznelujica, tanto en forma oral como escrita. Los hablantes nativos tienen el derecho legal de utilizar el idioma nizhneluzhice en sus relaciones con la administración pública $\left(\right.$ art.8 ${ }^{150}$. Sajonia aprobó una ley similar para proteger los derechos de los sorbos. Además, en algunos länder federales hay intervalos de tiempo especiales para la transmisión de televisión y Radio reservados para programas regionales y programas en idiomas minoritarios.

El gobierno de Austria estableció el Consejo asesor para las minorías como respuesta a la desintegración pacífica de Checoslovaquia en las repúblicas Checa y eslovaca en 1992.

\footnotetext{
${ }^{146}$ KUPPER, H. Das neue Minderheitenrecht in Ungarn (Südostinstitut Oldenbourg, München), 1998.P.115.

${ }^{147}$ Hungary: Act LXXVII of 1993 on the Rights of National and Ethnic Minorities. [Electronic resource]. Access mode: https://www.refworld.org/docid/4c3476272.html (Date accessed: 30.05.2019).

${ }^{148}$ Baumgartner, G. 6 x Österreich. Geschichte und aktuelle Situation der Volksgruppen (Drava Verlag, Klagenfurt, 1995).

${ }^{149}$ The Unification Treaty between the FRG and the GDR (Berlin, 31 August 1990. [Electronic resource]. Access mode: http://www.cvce.eu/obj/the_unification_treaty_between_the_frg_and_the_gdr_berlin_31_august_1990en- 2c391661-db4e-42e5-84f7-bd86108c0b9c.html (Date accessed: 01.06.2019).

${ }^{150}$ Gesetz über die Ausgestaltung der Rechte der Sorben/Wenden im Land Brandenburg (Sorben/WendenGesetz - SWG). [Electronic resource]. Access mode: https://bravors.brandenburg.de/gesetze/swg (Date accessed: 01.06.2019).
} 
3. Aprobación de los primeros instrumentos regionales relativos a los derechos de las minorías.

En 1992 se aprobó el tratado de Maastricht en el marco de la Unión Europea, en cuyo párrafo 1 del artículo 151.1 se establece que «la comunidad promueve el florecimiento de las culturas de los Estados miembros respetando su diversidad nacional y regional, al tiempo que destaca el patrimonio cultural común» ${ }^{151}$. En relación con la inclusión del multiculturalismo en los documentos constitutivos de la UE, se agregó una enmienda de 1992 al artículo 2 de la Constitución francesa ${ }^{152}$, a saber, «el idioma de la república es el francés». Durante las discusiones, el Senado dijo que la mención de las lenguas regionales no era necesaria, ya que Francia estaba comprometida con el respeto de las lenguas y culturas regionales ${ }^{153}$.Esta enmienda puede considerarse como una forma de proteger a Francia de posibles nuevas leyes de la comunidad Europea en materia de educación, cultura y política lingüística. Tras la enmienda, se aprobó la Ley Tubon de $1994^{154}$. El texto contenía disposiciones sobre la necesidad de enseñar idiomas regionales o extranjeros (por ejemplo, artículo 1.11). Las disposiciones de esta ley deberían haberse aplicado sin perjuicio de la legislación y las normas relativas a los idiomas regionales de Francia y sin perjuicio de su utilización (art.21) ${ }^{155}$.

Austria se convirtió en miembro de la Unión Europea en 1995 y participó activamente en las negociaciones para la redacción del artículo 21 de la carta de derechos fundamentales de la Unión Europea ${ }^{156}$, que prohíbe la discriminación por cualquier motivo, en particular por motivos de raza, color, origen étnico o social, idioma, religión o creencias, opinión política o de cualquier otra índole y pertenencia a una minoría nacional. En el marco del Consejo de Europa, Austria ha comenzado activamente a promover una mayor protección de las minorías nacionales en el marco del Convenio europeo para la protección de los derechos humanos y las libertades fundamentales ${ }^{157}$. En 1991, Austria presentó al Comité de Ministros del Consejo de Europa una propuesta sobre un protocolo adicional al Convenio europeo para la protección de las minorías nacionales. En él se definía el término «grupo étnico» y una amplia gama de derechos de las minorías. Sobre la base de esta propuesta, se elaboró un proyecto de protocolo, que fue aprobado por la Asamblea parlamentaria como recomendación 1201(1993).

\footnotetext{
${ }^{151}$ Treaty establishing the European Community. [Electronic resource]. Access mode: https://eurlex.europa.eu/legal-content/EN/TXT/?uri=CELEX\%3A12002E\%2FTXT (Date accessed: 31.05.2019).

${ }^{152}$ Constitution of France, 1958. [Electronic resource]. Access mode: https://www.conseilconstitutionnel.fr/sites/default/files/as/root/bank_mm/anglais/constiution_anglais_oct2009.pdf(Date accessed:31.05.2019).

${ }^{153}$ E' tienne, Bruno, Giordan, Henri \& Lafont, Robert (1992). Le temps du pluriel. Parise' ditions de l'Aube: La France dans l'Europe multiculturelle.-P.61.

${ }^{154}$ Loi № 94-665 du 4 août 1994 relative à l'emploi de la langue française. [Electronic resource]. Access mode:https://www.legifrance.gouv.fr/affichTexte.do?cidTexte=JORFTEXT000000349929\&dateTexte=\& categorieLien=id (Date accessed:31.05.2019).

${ }^{155} \mathrm{Id}$.

${ }^{156}$ Carta de derechos fundamentales de la Unión Europea, 7 de diciembre de 2000. [Recurso electrónico]. Modo de acceso: https://www.refworld.org.ru/docid/52e647374.html (fecha de solicitud: 22.05.2019).

${ }^{157}$ Convenio europeo para la protección de los derechos humanos y las libertades fundamentales. [Recurso electrónico]. Modo de acceso: https://www.refworld.org.ru/docid/52e647374.html (fecha de solicitud: 22.05.2019).
} 
En Italia, en la década de 1990, hubo una segunda ola de legislación regional relacionada con el apoyo y la promoción de las culturas locales. La razón de esta creciente atención por parte de la región se ve en parte en la intervención gradual del legislador regional en el ámbito de la protección de las minorías ${ }^{158}$.

En 1997 se aprobó la Ley regional para la promoción de la lengua y la cultura sardo $^{159}$. La región de Cerdeña prepara y coordina programas culturales anuales y plurianuales, garantiza la protección y la usabilidad del idioma sardo mediante la catalogación y conservación del Patrimonio cultural regional, y promueve, promueve y coordina los servicios necesarios para lograr los objetivos de la ley. En el artículo 17 de la ley se enumeran los proyectos destinados al conocimiento de la cultura y el idioma de Cerdeña en las siguientes esferas temáticas: lengua y literatura sardos, historia de Cerdeña, historia del arte de Cerdeña, tradiciones populares de Cerdeña, geografía y ecología de Cerdeña. La administración regional de Cerdeña tiene derecho a financiar los gastos de ejecución de proyectos realizados en escuelas de todos los niveles que, a través de los proyectos educativos mencionados en el artículo 17, llevan a cabo etapas experimentales basadas en los siguientes principios:

1) el aprendizaje de la lengua de Cerdeña en las diversas variantes utilizadas en la región, a partir de la coloquial;

2) estudio sistemático de diversos aspectos del Patrimonio ambiental, tecnológico, científico, artístico y cultural de Cerdeña, incluso mediante el uso del idioma sardo como vehículo;

3) desarrollo de programas educativos bilingües ${ }^{160}$.

Se han creado varias oficinas municipales de referencia lingüística para facilitar la comunicación. Sin embargo, el Comité asesor sobre la convención marco para la protección de los derechos de las minorías nacionales observa que la falta de información sobre el número de esos servicios de referencia y sobre la financiación no da la impresión de que esas actividades son suficientes para satisfacer las necesidades de más de un millón de personas de habla sardo ${ }^{161}$.

El 15 de diciembre de 1999 se aprobó en Italia la Ley Marco sobre las normas para la protección de las minorías lingüísticas históricas $(482 / 1999)^{162}$. Esta ley reconoce y protege los doce idiomas de las minorías históricas de la península. En la enseñanza de idiomas se garantiza, junto con el uso del italiano, el uso del idioma minoritario para la realización de actividades educativas (Art. Las regiones, las partes interesadas pueden

\footnotetext{
158 Palermo F.,Jens W., Diritto costituzionale comparato dei gruppi e delle minoranze (Cedam, Padova, 2008). -P.254.

${ }^{159}$ Legge Regionale 15 ottobre 1997 «Promozione e valorizzazione della cultura e della lingua della Sardegna». [Electronic resource]. Access mode:http://www.regione.sardegna.it/j/v/86?v=9\&c=72\&s=1\&file=1997026(Date accessed:13.10.2018). ${ }^{160}$ Legge Regionale 15 ottobre 1997 «Promozione e valorizzazione della cultura e della lingua della Sardegna». [Electronic resource]. Access mode:http://www.regione.sardegna.it/j/v/86?v=9\&c=72\&s=1\&file=1997026(Date accessed:13.10.2018). ${ }^{161}$ Fourth Opinion on Italy adopted on 19 November 2015. [Electronic resource]. Access mode:https://rm.coe.int/CoERMPublicCommonSearchServices/DisplayDCTMContent?documentId=090 00016806959b9(Date accessed:08.01.2019).

${ }^{162}$ Legge 15 Dicembre 1999, n. 482 «Norme in materia di tutela delle minoranze linguistiche storiche» pubblicata nella Gazzetta Ufficiale n. 297 del 20 dicembre,1999. [Electronic resource]. Access mode:http://www.camera.it/parlam/leggi/994821.htm(Date accessed:13.10.2018).
} 
concertar acuerdos con la empresa concesionaria de la autoridad de radiodifusión pública para realizar transmisiones periodísticas o programas en idiomas minoritarios en programas regionales de Radio y televisión (parte 2 del artículo 12). En virtud de la ley mencionada, la RAI tiene la obligación de proteger los idiomas minoritarios en las regiones con las que se han concertado acuerdos. Esta compañía emite 90 horas de programas de televisión en Friuli cada año. Se han concertado acuerdos similares con la provincia Autónoma de Bolzano, donde la compañía de Radio y televisión RAI transmite emisiones de Radio y televisión en alemán y ladino, mientras que en la región Autónoma del valle de Aosta, en francés ${ }^{163}$.

Por lo tanto, las minorías lingüísticas en Italia se pueden dividir en tres grupos:

1.Minorías súper protegidas en el Tirol del sur (con alemán y ladino), en Friuli Venezia Giulia (con Esloveno), en valle de Aosta (con francés);

2.Minorías reconocidas a las que se les ofrece protección potencial (las mencionadas en la ley Marco no. 482/1999, cuya protección depende de la activación de diversos instrumentos);

3.Minorías no reconocidas (y no protegidas) (minorías sinti y romaní) ${ }^{164}$.

La cuestión de las minorías nacionales estaba en la agenda de los países. En Polonia, esta cuestión surgió como resultado de la introducción de un sistema político democrático. En primer lugar, en agosto de 1989, el Sejm decidió establecer un Comité para las minorías nacionales y étnicas, integrado por diputados que representen a grupos étnicos específicos o en las circunscripciones de los cuales existan esos grupos. En segundo lugar, en su discurso parlamentario inaugural, Tadeusz Mazowiecki, el primer ministro no Comunista de Polonia del movimiento de solidaridad, dijo que Polonia es el hogar de las minorías nacionales y los polacos étnicos. En tercer lugar, en 1989 se decidió transferir la responsabilidad de financiar las instituciones de las minorías nacionales y sus actividades culturales del Ministerio del interior al Ministerio de cultura y artes. Como resultado, las autoridades polacas comenzaron a tratar a las minorías como legalmente iguales a los demás miembros de la sociedad polaca y comenzaron a establecer un marco jurídico que reflejara la situación especial e inusual de esos grupos en la sociedad, en particular en lo que respecta a la educación y la cultura:

- Artículo 35 de la Constitución de la República de Polonia, de 2 de abril de 1997, que garantiza a los ciudadanos polacos pertenecientes a minorías nacionales y étnicas la libertad de preservar y desarrollar su propio idioma ${ }^{165}$;

- Ley de asociaciones de Polonia de 7 de abril de 1989. Las minorías nacionales en Polonia son libres de formar asociaciones. En 1993 se registraron 109 asociaciones y 13 fundaciones de grupos de minorías nacionales en Polonia, y en 1994 unas 120 organizaciones realizaron esas actividades ${ }^{166}$. Los objetivos de las organizaciones eran

\footnotetext{
163 Quarta Opinione sull'Italia Adottata il 19 novembre 2015. [Electronic resource]. Access mode: http://www.libertaciviliimmigrazione.dlci.interno.gov.it/sites/default/files/allegati/iv_opinione_sullitalia.p df(Date accessed:30.11.2018).

${ }^{164}$ PALERMO F., JENS W., Diritto costituzionale comparato dei gruppi e delle minoranze (Cedam, Padova, 2008). -P.248.

165 Constitution of the Republic of Poland of 2 April 1997. [Electronic resource]. Mode of access: http://www.sejm.gov.pl/prawo/konst/rosyjski/kon1.htm (date accessed: 13.01.2019).

${ }^{166}$ Human Rights Committee's Consideration of Reports submitted by States parties under Article 40 of the International Covenant on Civil and Political Rights, Poland, CCPR/C/95/Add.8, 14 March 1997.
} 
promover el aprendizaje de idiomas. Las asociaciones fueron creadas, en particular, por bielorrusos, gitanos, franceses, lituanos, lemk.

- La Ley sobre el sistema educativo de 7 de septiembre de 1991, cuyo artículo 13 dice: «Las escuelas públicas permiten a los estudiantes mantener un sentido de identidad nacional, étnica, lingüística y religiosa, en particular permitiéndoles aprender su idioma, historia y cultura ${ }^{167} \gg$. La enseñanza del idioma minoritario se imparte a petición de los padres y puede impartirse en guarderías, grupos especiales, escuelas o grupos interescolares. La ley establece que los libros de texto necesarios y los manuales de capacitación de apoyo pueden recibir fondos adicionales del presupuesto estatal;

- La Ley de Radio y televisión de 29 de diciembre de 1992, en su artículo 21, establece las tareas de la Radio y la televisión del Estado derivadas de su misión pública, que incluyen la producción y la amplia cobertura y «prestar la debida atención a las necesidades de las minorías nacionales y étnicas y las comunidades que hablan el idioma regional, incluida la difusión de noticias en los idiomas de las minorías nacionales y étnicas y los idiomas regionales ${ }^{168} \gg$. La ley también obligaba a los directores de las oficinas de Radio y televisión públicas a considerar los candidatos propuestos por las organizaciones comunitarias de las minorías nacionales y étnicas y las comunidades que hablaban el idioma regional al designar los consejos de programación de las unidades sectoriales que emitían programas en idiomas minoritarios y regionales ${ }^{169}$. Por lo tanto, el legislador aseguró a las minorías el acceso a los medios de comunicación.

- La Ley sobre el idioma polaco, de 7 de octubre de 1999, se refiere a cuestiones como la protección del idioma polaco y su uso en actividades públicas y jurídicas en el territorio de la República de Polonia. Esta ley reconoce al polaco como el idioma oficial (art.4). No obstante, varias disposiciones afectan a los derechos de otros idiomas. En particular, los títulos y textos en polaco también pueden ir acompañados de versiones traducidas a idiomas extranjeros en los casos y el alcance determinados por el ministro responsable (art.10). Un contrato concertado y escrito en polaco puede ir acompañado de una versión en un idioma extranjero (art.8) ${ }^{170}$.Los periódicos locales en lenguas minoritarias comenzaron a publicarse regularmente en las regiones donde vivían minorías lingüísticas, como la revista «Mazur Stork» y el boletín de La alta Silesia ${ }^{171}$.

A principios de la década de 1990, las dos principales reformas del gobierno del Reino Unido fueron la devolución y el reconocimiento oficial de las lenguas minoritarias a nivel estatal. En 1991, el Departamento de educación de la oficina escocesa abogó por la inclusión del idioma escocés (gaélico) en el plan de estudios para niños de 5 a 14

\footnotetext{
167 The Act of 7 September 1991 on the system of education. [Electronic resource]. Access mode: https://eacea.ec.europa.eu/national-policies/eurydice/content/legislation-50_en (Date accessed: 13.01.2019).

${ }^{168}$ Broadcasting Act of 29 December 1992, Poland. [Electronic resource]. Access mode: https://www.krrit.gov.pl/Data/Files/_public/Portals/0/angielska/Documents/Regulations/broadcasting_act _28022013.pdf(Date accessed: 15.11.2018).

$\overline{169}$ Id.

${ }^{170}$ Act on the Polish language of 7 October 1999. [Electronic resource]. Access mode: https://ospcom.files.wordpress.com/2011/11/dr19.pdf(Date accessed:13.01.2019).

171 JAS-KOZIAEKIEWICZ, M. (2009), Podróże po mniejszym niebie. Dotowane pisma mniejszości niemieckiej w Polsce jako prasa środowiskowa po 1989 roku, Warszawa, Oficyna Wydawnicza Aspra-Jr; -P.111-114.
} 
años $^{172}$. En 1993, la oficina Europea de lenguas menos habladas reconoció el escocés(gaélico) como el idioma europeo de las minorías. En el período 1993/94 a 1997/98, la enseñanza primaria secundaria en gaélico aumentó en más del 15\%, y los programas de Radio y televisión en gaélico se expandieron rápidamente ${ }^{173}$.

En Gales, se aprobó la Ley de idioma galés de 1993. A diferencia de la ley de idioma galés de 1967, es más estructurada y específica, y esto ha permitido la difusión del uso del idioma galés ${ }^{174}$. Esta ley regula:

- uso del idioma galés en documentos procedentes de empresas galesas y de organizaciones benéficas galesas;

- uso de señales de tráfico en galés e inglés;

- permitir el uso del idioma galés;

- establecimiento del Consejo de idioma galés. El Consejo de idioma galés tiene por objeto promover y facilitar el uso del idioma galés; velar por que las autoridades públicas elaboren planes que garanticen la aplicación del principio de que el inglés y el galés deben tratarse en condiciones de igualdad en la administración de asuntos públicos y la administración de justicia en Gales; y adoptar disposiciones adicionales sobre el idioma galés $^{175}$.

En 1997 se aprobó la Ley del gobierno de Gales, en cuyo artículo 47 se estipula que el inglés y el galés gozan de igualdad de trato y que todas las políticas deben redactarse en ambos idiomas ${ }^{176}$.En Irlanda del Norte, la transferencia de poderes fue parte integral del llamado Acuerdo del viernes Santo, que fue sometido a referéndum en $1998^{177}$. El acuerdo reconoce la importancia del respeto, la comprensión y la tolerancia de la diversidad linguiística, incluso en Irlanda del Norte, el idioma irlandés, el idioma Ulster-escocés y los idiomas de las diversas minorías étnicas que forman parte de la riqueza cultural. En particular, con respecto al idioma irlandés, se definieron las siguientes obligaciones:

- adoptar medidas decisivas para promover el uso del idioma;

- facilitar y promover el uso del lenguaje en la vida pública y privada, siempre que haya una demanda adecuada;

- tratar de eliminar las restricciones que impidan la preservación o el desarrollo del lenguaje.

Por lo tanto, de 1989 a 2000, la cuestión de las minorías lingüísticas se convirtió en uno de los principales temas de la política nacional. En los países se siguió trabajando en la reglamentación de la protección de las minorías linguísticas, de conformidad con los instrumentos regionales. En particular, en Polonia, la política estatal sobre las minorías

\footnotetext{
172 MURDOCH, S. Language Politics in Scotland. Aberdeen University Scots Leid Quorum. [Electronic resource]. Access mode: http://scotsyett.com/download/lip.pdf (Date accessed:05.04.2019).

${ }^{173}$ MCLEOD, W. (2001). Gaelic in the New Scotland: Politics, Rhetoric and Public Discourse. Journal of Ethnopolitics and Minority Issue in Europe. [Electronic resource]. Access mode: http://www.ecmi.de/jemie/download/JEMIE02MacLeod28-11-01.pdf (Date accessed: 05.04.2019).

${ }^{174}$ POGGESCH, G. I diritti linguistici. Un'analisi comparata. Rome: Carrocci Editore. - 2010. -P.183.

${ }^{175}$ Welsh Language Act, 1993. [Electronic resource]. Access mode: https://www.legislation.gov.uk/ukpga/1993/38/contents (Date accessed: 09.04.2019).

${ }^{176}$ Government of Wales Act. (1998). [Electronic resource]. Access mode: https://www.legislation.gov.uk/ukpga/1998/38/contents (Date accessed:09.04.2019).

${ }^{177}$ United Kingdom public sector information website / / URL: http:// www.gov.uk (accessed 22.04.2019).
} 
nacionales fue «despolitizada», mientras que en Francia la política se centró en la difusión, el desarrollo y el mantenimiento de la lengua estatal, y en la contención del pluralismo cultural. En Bélgica, la política lingüística era liberal, pero debido a la diferente situación económica de las regiones lingüísticas, la lucha entre las minorías lingüísticas persistió. El proceso de devolución ha concluido en el Reino Unido de gran Bretaña e Irlanda del Norte y el Estado ha comenzado a adoptar medidas positivas para promover los idiomas regionales y minoritarios. Resumiendo, los países, podemos decir que, en su mayoría, la política lingüística de los Estados estaba dirigida al multilingüismo, pero al mismo tiempo cada Estado trató de extender su esfera de influencia lingüística a grandes territorios.

\section{Conclusión}

Después de haber estudiado la experiencia de los países extranjeros en diferentes épocas, las políticas públicas sobre lenguas minoritarias pueden variar, desde la asimilación forzada hasta la autonomía cultural. Sin embargo, como muestra la experiencia histórica, el Estado generalmente busca la integración, que en el campo lingüístico se logra a través de la satisfacción de la necesidad de comprensión mutua y el apoyo a la lengua mayoritaria. Esta política resulta especialmente dura en momentos en que el mercado único, el sistema educativo unificado, el sistema administrativo unificado, etc. comienzan a formarse dentro del Estado ${ }^{178}$.

\section{Fuentes de consultadas}

Convenio europeo para la protección de los derechos humanos y las libertades fundamentales. [Recurso electrónico]. Modo de acceso: https://www.refworld.org.ru/docid/52e647374.html (fecha de solicitud: 22.05.2019). Treaty establishing the European Community. [Electronic resource]. Access mode: https://eur-lex.europa.eu/legal-content/EN/TXT/?uri=CELEX\%3A12002E\%2FTXT (Date accessed: 31.05.2019).

Carta de derechos fundamentales de la Unión Europea, 7 de diciembre de 2000. [Recurso electrónico]. Modo de acceso: https://www.refworld.org.ru/docid/52e647374.html (fecha de solicitud: 22.05.2019).

Bonn-Copenhagen Declarations 1955. [Electronic resource]. Access mode: https://www.ecmi.de/about/history/german-danish-border-region/bonn-copenhagendeclarations/(Date accessed:20.05.2019).

\section{Actos normativos y legales de Italia}

The Constitution of the Italian Republic 1948. [Electronic resource]. Access mode: https://www.senato.it/documenti/repository/istituzione/costituzione_inglese.pdf(Date accessed:11.01.2018).

${ }^{178}$ PSHEGUSOVA G.S., IVANOVA D.N. Language policy in multicultural region: retrospective analysis// Humanities of the South of Russia. - P.67. 
Statuto Albertino. [Electronic resource]. Access mode: http://www.quirinale.it/allegati_statici/costituzione/Statutoalbertino.pdf (Date accessed: 08.11.2018).

Statuto speciale per la Valle d'Aosta, Legge costituzionale 26 febbraio 1948. [Electronic resource]. mode:http://www.regione.fvg.it/rafvg/export/sites/default/RAFVG/GEN/statuto/allegati /statutoGiugno2003.pdf (Date accessed: 18.05.2019).

Statuto speciale per il Trentino-Alto Adige, Legge costituzionale 26 febbraio 1948. [Electronic resource]. Access mode:http://www.consiglio-bz.org/download/1.Statuto-diAutonomia-1948.pdf (Date accessed: 18.05.2019).

Statuto Speciale della regione autonomia Friuli n Venezia Giulia, Legge costituzionale 31 gennaio 1963, n. 1 e successive modifiche ed integrazioni. [Electronic resource]. Access mode:http://www.regione.fvg.it/rafvg/export/sites/default/RAFVG/GEN/statuto/allegati /statutoGiugno2003.pdf (Date accessed: 18.05.2019).

State Treaty (with annexes and maps) for the re-establish-ment of an independent and democratic Austria, on 15 May 1955. [Electronic resource]. Access mode:https://www.dipublico.org/100823/state-treaty-with-annexes-and-maps-for-the-reestablish\%C2\%ADment-of-an-independent-and-democratic-austria-signed-at-viennaon-15-may-1955/ (Date accessed: 20.05.2019).

Legge Regionale 15 ottobre 1997 «Promozione e valorizzazione della cultura e della lingua della Sardegna». [Electronic resource]. Access mode:http://www.regione. sardegna.it/j/v/86? $\mathrm{v}=9 \& \mathrm{c}=72 \& \mathrm{~s}=1 \&$ file=1997026(Date accessed:13.10.2018).

Legge 15 Dicembre 1999, n. 482 «Norme in materia di tutela delle minoranze linguistiche storiche» pubblicata nella Gazzetta Ufficiale n. 297 del 20 dicembre,1999. [Electronic resource]. Access mode:http://www.camera.it/parlam/leggi/994821.htm(Date accessed:13.10.2018).

Quarta Opinione sull'Italia Adottata il 19 novembre 2015. [Electronic resource]. Access mode:

http://www.libertaciviliimmigrazione.dlci.interno.gov.it/sites/default/files/allegati/iv_op inione_sullitalia.pdf(Date accessed:30.11.2018).

\section{Actos normativos y legales de Alemania}

The Unification Treaty between the FRG and the GDR (Berlin, 31 August 1990. [Electronic resource]. Access mode: http://www.cvce.eu/obj/the_unification_treaty_between_the_frg_and_the_gdr_berlin_3 1_august_1990-en- 2c391661-db4e-42e5-84f7-bd86108c0b9c.html (Date accessed: 01.06.2019).

Constitución del Reich Alemán de 1919. [Electronic resource]. Access mode: http:// www.documentarchiv.de/wr/wrv.html\#ERsTER_AbsCHNITT02. (Date accessed: 06.12.2018).

Burgenländisches Landesschulgesetzes 1937 über die Regelung desVolksschulwesens im Burgenland [Regional School Act of Burgenland 1937 on the Regulation of the Primary School System inBurgenland]. LGB1. Nr. 40/1937. 
Basic Law for the Federal Republic of Germany 1949. [Electronic resource]. Access mode: https://www.btg-bestellservice.de/pdf/80201000.pdf (Date accessed:07.05.2019). The Federal Law for minority schooling from 1959 (BGBl. 101/1959). [Electronic resource].

Access mode:https://www.ris.bka.gv.at/Dokumente/BgblPdf/1959_101_0/1959_101_0.pdf (Date accessed:20.05.2019).

Bundesgesetz über die Rechtsstellung der Volksgruppen in Österreich(BGB1. № 396/1976[Electronic resource]. Access mode: https://www.ris.bka.gv.at/Dokumente/BgblPdf/1976_396_0/1976_396_0.pdf（Date accessed: 21.05.2019).

Gesetz über die Ausgestaltung der Rechte der Sorben/Wenden im Land Brandenburg (Sorben/Wenden-Gesetz - SWG). [Electronic resource]. Access mode: https://bravors.brandenburg.de/gesetze/swg (Date accessed: 01.06.2019).

\section{Actos normativos y legales del Reino Unido}

First Report on the Select Committee on Emigration in Scotland. The House of Commons.1841. -P.19.

The Act of Union 1536. [Electronic resource]. Access mode:http://www.bbc.co.uk/wales/history/sites/themes/periods/tudors_04.shtml (date accessed: 16.11.2018).

Education Act 1918. [Electronic resource]. Access mode: http://www.legislation.gov.uk/ukpga/Geo5/8-9/39 (Date accessed: 21.05.2019).

Welsh Courts Act, (1942). [Electronic resource]. Access mode: http://www.legislation.gov.uk/ukpga/Geo6/5- 6/40/enacted (Date accessed: 09.04.2019). Welsh Language Act, 1967. [Electronic resource]. Access mode: http://www.legislation.gov.uk/ukpga /1967/66/enacted (Date accessed: 06.04.2019).

Education (Scotland) Act 1980. [Electronic resource]. Access mode: https://www.legislation.gov.uk/ukpga/1980/44/contents (Welsh Language Support Service for School. [Electronic resource]. Access mode: http:// www.wales.gov.uk/statistics-and-research/re(Date accessed: 21.05.2019).

Broadcasting Act. [Electronic resource]. Access mode: http://www.legislation.gov.uk/ ukpga/1981/68/contents (Date accessed: 09.04.2019).

The Grants for Gaelic Language Education (Scotland) Regulations 1986. [Electronic resource]. Access mode: http://www.legislation.gov.uk/uksi/1986/410/contents/made (Date accessed: 21.05.2019).

Education Reform Act 1988. [Electronic resource]. Access mode: http://www.legislation.gov.uk/ukpga/1988/40/part/II/chapter/I (Date accessed: 21.05.2019).

Welsh Language Act, 1993. [Electronic resource]. Access mode: https://www.legislation.gov.uk/ukpga/1993/38/contents (Date accessed: 09.04.2019).

Government of Wales Act. (1998). [Electronic resource]. Access mode: https://www.legislation.gov.uk/ukpga/1998/38/contents (Date accessed:09.04.2019).

United Kingdom public sector information website / / URL: http:// www.gov.uk (accessed 22.04.2019). 
IUS ET SCIENTIA (ISSN 244-8478) 2019, Vol. 5, nº 2, pp. 145-189. ANÁLISIS CIENTÍFICO-JURÍDICO COMPARATIVO DE LA POLÍTICA LINGÜÍSTICA EN RELACIÓN CON LAS MINORÍAS NACIONALES. Iliana elyana.valiulina@gmail.com Universidad de los Urales (Rusia) Recibido: 17/09/2019. Aceptado: 10/10/2019 DOI: http://doi.org/10.12795/IESTSCIENTIA.2019.i02.07

\section{Actos normativos y legales de Polonia}

Konstitutsionnaya Hartiya Tsarstva Polskogo 1815 goda. [Elektronnyiy resurs]. Rezhim dostupa: http://www.pereplet.ru/history/Russia/Imperia/Alexandr_I/kx1815.html(data obrascheniya: 08.02.2019).

Constitution of the Republic of Poland, March 17 of 1921. [Electronic resource]. Access mode:http://libr.sejm.gov.pl/tek01/txt/kpol/e1921.html (Date accessed: 08.11.2018).

The Constitution of the Republic of Poland 1952. [Electronic resource]. Access mode: http://libr.sejm.gov.pl/tek01/txt/kpol/e1952a-r7.html (Date accessed:20.05.2019).

The Act of 7 September 1991 on the system of education. [Electronic resource]. Access mode: https://eacea.ec.europa.eu/national-policies/eurydice/content/legislation-50_en (Date accessed: 13.01.2019).

Broadcasting Act of 29 December 1992, Poland. [Electronic resource]. Access mode: https://www.krrit.gov.pl/Data/Files/_public/Portals/0/angielska/Documents/Regulations/ broadcasting_act_28022013.pdf(Date accessed: 15.11.2018).

Constitution of the Republic of Poland of 2 April 1997. [Electronic resource]. Mode of access: http://www.sejm.gov.pl/prawo/konst/rosyjski/kon1.htm (date accessed: 13.01.2019).

Human Rights Committee's Consideration of Reports submitted by States parties under Article 40 of the International Covenant on Civil and Political Rights, Poland, CCPR/C/95/Add.8, 14 March 1997.

Act on the Polish language of 7 October 1999. [Electronic resource]. Access mode: https://ospcom.files.wordpress.com/2011/11/dr19.pdf(Date accessed:13.01.2019).

\section{Normative-legal acts of Austria}

The Austrian Constitution of 1867. Walter Farleigh Dodd, ed., Modern Constitutions: A Collection of the Fundamental Laws of Twenty-two of the Most Important Countries of the World, With Historical and Bibliographical Notes. Chicago: The University of Chicago Press, 1909.

The Constitution of the Republic of Austria 1920. [Electronic resource]. Access mode: https://www.constituteproject.org/constitution/Austria_2013.pdf?lang=en (Date accessed:20.05.2019).

The Federal Constitutional law of Austria, 1920. [Electronic resource]. Access mode: http://constitutionnet.org/sites/default/files/Austria\%20_FULL_\%20Constitution.pdf (Date accessed: 03.05.2019).

\section{Actos normativos y legales de Francia}

The Ordinance of Villers-Cotterêts. [Electronic resource]. Access mode: https://ipfs.io/ipfs/QmXoypizjW3WknFiJnKLwHCnL72vedxjQkDDP1mXWo6uco/wik i/Ordinance_of_Villers-Cotterêts.html (date accessed: 16.11.2018).

The Ordonnance de 1563, dite de Roussillon. [Electronic resource]. Access mode: https://gallica.bnf.fr/ark:/12148/bpt6k858577n(date accessed: 10.02.2019). 
Constitution of France, 1958. [Electronic resource]. Access mode: https://www.conseilconstitutionnel.fr/sites/default/files/as/root/bank_mm/anglais/constiution_anglais_oct20 09.pdf(Date accessed:31.05.2019).

Loi № 51-46 du 11 janvier 1951 relative à l'enseignement des langues et des dialectes locaux. [Electronic resource]. Access mode: http://www.axl.cefan.ulaval.ca/europe/France-loi_Deixonne-texte-1951.htm(Date accessed:11.02.2019).

Loi du 2 août 1963 sur l'emploi des langues en matière administrative. // Moniteur belge du 22 août 1962.

Loi № 75-620 du 11 juillet 1975 relative à l'éducation «Loi Haby», version consolidée au 21 juin 2000. [Electronic resource]. Access mode: http://www.observatorioccitan.org/documents/1975_Loi_Haby.pdf (Date accessed:11.02.2019).

Loi № 94-665 du 4 août 1994 relative à l'emploi de la langue française. [Electronic resource].

Access mode:https://www.legifrance.gouv.fr/affichTexte.do?cidTexte=JORFTEXT0000003499 29\&dateTexte=\&categorieLien=id (Date accessed:31.05.2019).

\section{Actos normativos y legales de Hungría}

The Constitution of the Republic of Hungary, Act XX of 1949. [Electronic resource]. Access mode: https://www2.ohchr.org/english/bodies/cescr/docs/E.C.12.HUN.3Annex2.pdf (Date accessed:07.05.2019).

Hungary: Act LXXVII of 1993 on the Rights of National and Ethnic Minorities. [Electronic resource]. Access mode: https://www.refworld.org/docid/4c3476272.html (Date accessed: 30.05.2019).

\section{Actos jurídicos normativos de Bélgica}

Loi de 15 juin 1935 concernant l'emploi des langues en matière judiciaire [Act concerning the use of languages in judicial matters] of June 15,1935, «Moniteur Belge» [«M.B.»], 1935.06.22, [Electronic resource]. Access mode: http://www.axl.cefan.ulaval.ca/europe/belgiqueetat-loi1935.htm(Date accessed:15.10.2018).

Law Governing the Use of Languages in Administrative Matters. Coordinated on July 18, 1966. [Electronic resource]. Access mode: https://www.uottawa.ca/clmc/kingdombelgium-law-governing-use-languages-administrative-matters(Date accessed: 26.11.2018).

\section{Jurisprudencia}

Belgium Linguistics Case - «In the case "relating to certain aspects of the laws on the use of languages in education in Belgium» v Belgium (Application no 1474/62; 1677/62; 1691/62; 1769/63; 1994/63; 2126/64). [Electronic resource]. Access mode:http://www.equalrightstrust.org/ertdocumentbank/Microsoft\%20Word\%20$\%$ 20Belgian\%20linguistics\%20case.pdf ${ }^{1}$ (Date accessed:26.11.2018). 
Judgment of the European Court of Human Rights of case «Relating to certain aspects of the laws on the use of languages in education in Belgium» v. Belgium (Merits). [Electronic resource]. Access mode; https://minorityrights.org/wp-content/uploads/oldsite-downloads/download-223-Belgian-Linguistic-case-full-case.pdf(Date accessed:11.11.2018).

\section{Lista de referencias}

1. AGER, D. (1999) Identity Insecurity and Image: France and Language. -1999. P.31.

2. AGER, D. Language policy in Britain and France: the processes of policy. London: Cassell. - 1996. -P.168.

3. ALPATOV V. M. 150 iazykov i politika: 1917-2000. - M., 2000.

4. ANDREWS, «The Very Dogs in Belfast». -P.87.

5. BAKKER, E. Minority Conflicts in Slovakia and Hungary? (Labyrint Publication, Ijssel 1997), note 14, $151 \mathrm{f}$.

6. BALL M., MULLER N. The Celtic Languages. Routledge. [Electronic resource]. Access mode: https://books.google.it/books?id=lDZASvUihk0C\&pg=PT663\&lpg=PT663\&dq=1846+ by+William+Williams++welsh+language\&source=bl\&ots=Z9ft59DUiT\&sig=ACfU3U 2JDwY27H1ADNUViMMPaetCxiD4Hw\&hl=en\&sa=X\&ved=2ahUKEwi4nuuHn6Lh AhVCKuwKHRj9ACEQ6AEwB3oECAgQAQ\#v=onepage $\& q=1846 \% 20$ by $\% 20$ Willia $\mathrm{m} \% 20$ Williams\%20\%20welsh\%20language $\& \mathrm{f}=$ false (Date accessed: 27.03.2019);

7. BAMBUST I., KRUGER A., KRUGER T. Constitutional and judicial language protection in multilingual states: A brief overview of South Africa and Belgium. [Electronic resource]. Access mode: https://core.ac.uk/download/pdf/43326647.pdf (Date accessed: 11.11.2018).

8. BAUMGARTNER, G. 6 x Österreich. Geschichte und aktuelle Situation der Volksgruppen (Drava Verlag, Klagenfurt, 1995.

9. BEHEYDT L., The Linguistic Situation in a New Belgium, in in languages in contact and conflict, contrasting experiences in the Netherlands and Belgium //Sue Wright ed., Multilingual Matters Ltd. 1995. -P.48,52.

10. Between Hitler and Stalin. [Electronic resource]. Access mode: http://www.ucrdc.org/HI-POLONIZATION.html(Date accessed: 04.05.2019).

11. BOYLAN, H. A Dictionary of Irish Biography (3rd ed.). Dublin: Gill and MacMillan. -1998. -P. 306.

12. BRIGITTE M., Vergleichende Studien zur Situation der Minderheiten in Ungarn und Rumänien (1989- 1996) unter besonderer Berücksichtigung der Roma (Peter Lang, Frankfurt et.al., 1999.-P. 52.

13. BROWN, I. (2006). Edinburgh History of Scottish Literature: Enlightenment, Britain and Empire (1707-1918). Edinburgh: Edinburgh

14. CAMPBELL, J. L., (1945) Gaelic in Scottish Education and Life: Past, Present and Future. Edinburgh: W. \& AK Johnston. -P.59-60.

15. CAVANAUGH, J. R. A Modern Questione della Lingua: The Incomplete Standardization of Italian in a Northern Italian Town. The Journal of the Society for the Anthropology of Europe 8, no. 1 (Spring/Sumer, 2008). -P.22. 
IUS ET SCIENTIA (ISSN 244-8478) 2019, Vol. 5, nº 2, pp. 145-189. ANÁLISIS CIENTÍFICO-JURÍDICO COMPARATIVO DE LA POLÍTICA LINGÜÍSTICA EN RELACIÓN CON LAS MINORÍAS NACIONALES. Iliana elyana.valiulina@gmail.com Universidad de los Urales (Rusia) Recibido: 17/09/2019. Aceptado: 10/10/2019 DOI: http://doi.org/10.12795/IESTSCIENTIA.2019.i02.07

16. CHISHOLM, C. The Clearance of the Highland Glens (1878). [Electronic resource]. Access mode: http://www.electricscotland.com/history/articles/clearance.htm (Date accessed: 24.03.2019).

17. Committee on the Administration of Justice, Staid agus stádas na Gaeilge i dtuaisceart na hÉireann. - P.29.

18. CORTELAZZO, M. Avviamento Critico Allo Studio Della Dialettologia Italiana. Vol. III. Pisa:Pacini,1972. -P.14.

19. CROWLEY, The Politics of Language in Ireland, The Proceedings of the Barra Ó Donnabháin Symposium. -2007. -P.134.

20. DAVIES, N. 2005. God's Playground. A History of Poland in Two Volumes. Oxford: University Press.-P.442.

21. DAVIS J. The Welsh language: A History. The University of Welsh Press.2014. - P.192.

22. DEMESHEVA Y. V. Konstitutsionno-pravovyie mehanizmyi razresheniya etnolingvisticheskogo konflikta v Belgii: dis. na soi. uchenoy stepeni k. yu. n. [Electronic resource]. Access mode: https://www.hse.ru/data/2015/11/20/1081920950/FINAL odt DEMEShEVA POLNYiY TEKST.pdf (Date accessed: 12.11.2018).

23. DENECKERE G. 1900: België op het breukvlak van twee eeuwen//Lannoo Uitgeverij, 2006.-P.186.

24. DUGGAN, C. A Concise History of Italy. Cambridge: University Press, 2012.P.96.

25. DZIENNIK U. RP 1922. Nr 90. Poz. 829. [Electronic resource]. Access mode: http://prawo.sejm.gov.pl/isap.nsf/download.xsp/WDU19220900829/O/D19220829.pdf( Date accessed: 08.02.2019).

26. Education: Primary Public Education- National Schools from 1831. Encyclopedia of Irish History and Culture. [Electronic resource]. Access mode: https://www.encyclopedia.com> (Date accessed: 01.04.2019).

27. E' tienne, Bruno, Giordan, Henri \& Lafont, Robert (1992). Le temps du pluriel. Parise' ditions de l'Aube: La France dans l'Europe multiculturelle. -P.61.

28. European Convention on Human Rights Year: 1974.Council of Europe/Conseil de L'Europe Martinus Nijhoff Publishers, 1st of March, 1976 г. - P.560.

29. FINK, C., «Stresemann's Minority Policies, 1924-29», Journal of Contemporary History 14: 3, 1979. -P.404.

30. FOSTER R.F., Modern Ireland 1600-1972, London 1988, pp 447-8; S.J. Connolly (ed.), The Oxford companion to Irish history, Oxford 1998.-P. 215, 253, 338-9.

31. GOETHEM V. H., De taaltoestanden in het Vlaams-Belgisch gerecht, 1795-1935, Verhandelingen van de Koninklijke Academie voor Wetenschappen, Letteren en Schone Kunsten van Belgie, 1990. -P.162-178.

32. GOODEN J. The law and the Welsh language. [Electronic resource]. Access mode: $\quad$ https://www.bbc.co.uk/blogs/wales/entries/020f5be9-73a7-3491-a4dd57fc6875eade (Date accessed:22.04.2019).

33. HENDRIK V., Language and Territoriality in Flanders in a historical and international context. [Electronic resource]. Access mode: http://www.flanders.be/en/publications/detail/language-and-territoriality-in- flanders-ina-historical-and-international-context(Date accessed: 01.10.2018). 
34. HERDERJ.G. Briefe zur Beforderung der Humanitat. Rudolstadt, O.D.-P.213216.

35. HINDLEY, R. 1990. The Death of the Irish language: A qualified obituary London: Routledge. -1990.-P.24.

36. HOOGHE L., Belgium: Hollowing the Center, in federalism. unitarism, and territorial cleavages (Ugo Amoretti \& Nancy Bermeo eds., Johns Hopkins Press 2002). [Electronic resource]. Access mode: http://www.unc.edu/ hooghe/assets/docs/books/princeton_finaldraft.pdf (Date accessed: 09.11.2018).

37. Italy: Aostans. [Electronic resource]. Access mode: https://minorityrights.org/minorities/aostans/(Date accessed: 10.01.2019).

38. JAS-KOZIAEKIEWICZ, M. (2009), Podróże po mniejszym niebie. Dotowane pisma mniejszości niemieckiej w Polsce jako prasa środowiskowa po 1989 roku, Warszawa, Oficyna Wydawnicza Aspra-Jr; -P.111-114.

39. KADYROVA, N.A. Evolyutsiya protsessov po zaschite prav lingvisticheskih menshinstv V Evrope.[Elektronnyiy resurs]. Rezhim dostupa: http://sciarticle.ru/stat.php?i=1454333848 (data obrascheniya: 16.11.2018).

40. KARNAUHOVA, E. E. Izmenenie strategii vneshney kulturnoy i yazyikovoy politiki Germanii na sovremennom etape// Vestnik Nizhegorodskogo universiteta im. N.I.Lobachevskogo, 2012b.-№1(2). -P.374.

41. KOHN, H. Napoleon and the Age of Nationalism, Journal of Modern History vol. 21 no.1 (1955). - P.30.

42. KUPPER, H. Das neue Minderheitenrecht in Ungarn (Südostinstitut Oldenbourg, München), 1998.-P.115.

43. Language facilities in the Brussels Periphery. Evolution, areas of conflict and linguistic practices. [Electronic resource]. Access mode: http://www.briobrussel.be/assets/brusselse\%20themas/bt9summary.pdf(Date accessed:16.11.2018).

44. Language planning and policy in europe. the Baltic states, ireland and italy [Text] // language planning and policy in europe / ed. by R. B. Kaplan and R. B. Baldauf. Multilingual matters ltd., 2008. - v. 3. -P.303.

45. Llyfrgell Genedlaethol Cymru - The National Library of Wales (a). The Blue Books of 1847. n.d. 9 May 2016. [Electronic resource]. Access mode: https://www.llgc.org.uk/discover/digital-gallery/printed- material/the-blue-books-of1847/>. (Date accessed: 27.03.2019).

46. LODGE, R. A. French: From Dialect to Standard, London, Routledge,1993.P.192.

47. MACKINNON, K. The lion's tongue: the story of the original and continuing language of the Scottish people. Inverness: Club Leabhar. -1974. -P.54.

48. MAUREEN, W. The decline of the Irish language // A View of the Irish language. Edited by Brian O'Cuiv. -1969.-P.89.

49. MAURO, D.T. Storia Linguistica Dell'Italia Unita. [Electronic resource]. Access mode:

https://www.laterza.it/index.php?option=com_laterza\&task=schedalibro\&isbn=9788842 096092(Date accessed: 23.11.2018). 
50. MCLEOD, W. (2001). Gaelic in the New Scotland: Politics, Rhetoric and Public Discourse. Journal of Ethnopolitics and Minority Issue in Europe. [Electronic resource]. Access mode: http://www.ecmi.de/jemie/download/JEMIE02MacLeod28-11-01.pdf (Date accessed: 05.04.2019).

51. MCRAE, K.D. Conflict and Compromise in Multilingual Societies. (Belgium) (Waterloo: Wilfred Laurier Press, 1986). -P.221.

52. MURDOCH, S. Language Politics in Scotland. Aberdeen University Scots Leid Quorum. [Electronic resource]. Access mode: http://scotsyett.com/download/lip.pdf (Date accessed:05.04.2019).

53. National minorities, minority and regional languages in Germany. [Electronic resource]. Access mode:

https://www.bmi.bund.de/SharedDocs/downloads/EN/publikationen/2016/nationalminorities-minority-and-regional-languages-in-germany.pdf?_blob=publicationFile (Date accessed: 20.05.2019).

54. NELDE P. H., Language in Contact and Conflict: The Belgian Experience and the European Union, in languages in contact and conflict, contrasting experiences in the Netherlands and Belgium//Sue Wright ed., Multilingual Matters Ltd 1995. -P.65,66.

55. NESTEROVA, T.P. Ot reformyi Dzhentile k reforme Bottai: obrazovatelnaya politika Italii v 1920- 1930-h gg. [Tekst] / T.P.Nesterova //Izv. Uralskogo gos. universiteta. - 2008. - № 59. - P. 118-126.

56. NIPPERDEY Th. Nachdenken uber die Deutsche Geschichte. Munchen,1986.

57. OBOLENSKAYA S. V. Germanskaya natsionalnaya ideya na sluzhbe Bismarka i ee sudba v XX veke// Evropeyskie revolyutsii 1848 goda. «Printsip natsionalnosti v politike i ideologii.-M.: Indrik, 2001.-P.76-77.

58. OBOLENSKAYA S.V. Rozhdenie germanskoy natsionalnoy idei// Evropeyskie revolyutsii 1848 goda. «Printsip natsionalnosti v politike i ideologii. -M.: Indrik, 2001.P.48.

59. O'Fiaich, T. The language and political history // A view of the Irish language. Edited by B. O'Cuiv.-1969.-P.101.

60. OTWINOWSKA, A. Cognate Vocabulary in Language Acquisition and Use: Attitudes, Awareness, Activation.[Electronic resource]. Access mode: https://books.google.it/books?id=5teOCgAAQBAJ\&printsec $=$ frontcover $\& h \mathrm{l}=\mathrm{it} \# \mathrm{v}=\mathrm{onep}$ age \&q\&f=false (date accessed:23.11.2018).

61. PALERMO F., JENS W., Diritto costituzionale comparato dei gruppi e delle minoranze (Cedam, Padova, 2008). -P.254.

62. PASCU S., A History of Transylvania. [Electronic resource]. Access mode: http://www.hungarianhistory.com/lib/pas/pas14.htm (Date accessed: 30.04.2019).

63. POGGESCHI, G. I diritti linguistici. Un'analisi comparata. Rome: Carrocci Editore. - 2010. -P.183.

64. Practice of Minority Protection in Central Europe: Austria. [Electronic resource]. Access mode: https://www.amazon.co.uk/Practice-Minority-Protection-SchriftenreiheEuropaischen/dp/3832960252 (Date accessed: 06.05.2019).

65. RUYS, M. (1981) Die Flamen. Ein Volk in Bewegung, eine werdende Nation. Tielt. -P.46.

66. SERIANNI, L. La Lingua nella Storia d'Italia. Milan: Società Dante Alighieri, Libri Scheiwiller, 2002. -P.293,341. 
67. University Press. -P.29.

68. Sayt obschestvenno-politicheskogo zhurnala Planeta// URL: https://planeta.by/article/687 (Date accessed:22.04.2019).

69. School history. [Electronic resource]. Access mode: http://www.bunscoilphobalfeirste.com/Page/School-History/369/Index.html (Date accessed: 21.05.2019).

70. SCHOT B., Nation oder Staat. -P.40.

71. SMITH, J. A., (1968) «The Position of Gaelic and Gaelic culture in Scottish Education in Thomson», D.S., \& Grimble, I. (ed), (1968) The Future of the Highlands. London: Poutledge \& Kegan Paul. - P.64.

72. SORCHA, F., Reversing Language Shift in France: The Breton Case. [Electronic resource]. Access mode:https://www.scss.tcd.ie/undergraduate/computer-sciencelanguage/bacsll_web/foy0102.pdf (Date accessed:11.02.2018).

73. SYLVAIN S. The role and importance of the Welsh language in Wales's cultural independence within the United Kingdom. [Electronic resource]. Access mode: https://dumas.ccsd.cnrs.fr/dumas-00719099/document (Date accessed: 05.04.2019).

74. The Flemish Movement: How language shaped Belgium. [Electronic resource]. Access mode: http://www.brusselstimes.com/magazine2/12050/the-flemish-movementhow-language-shaped-belgium(Date accessed:09.01.2018).

75. The Spring of Nations (1848). [Electronic resource]. Access mode: http://grial4.usal.es/MIH/SpringNations2/en/presentation.html (Date accessed: 30.04.2019).

76. TSCHUPPIK, K. (1928). Franz Joseph I., Der Untergang eines Reiches. Hellerau bei Dresden: Avalun-Verlag. -P.247.

77. ULF, T. Weimar Germany's foreign policy and the protection of minorities: The case of the German minority in Poland. Historia Caribe - Volumen IX N 25 - JulioDiciembre, 2014. -P.45.

78. ULRIKE V., Hüning M. One Nation, One Language? The Case of Belgium. [Electronic resource]. Access mode: http://www.academia.edu/1056036/One_nation_one_language_The_case_of_Belgium (Date accessed: 14.10.2018).

79. ULRICH, V. Os Berlin-Rim. Soyuz Mussolini i Gitlera. [Electronic resource]. Access mode: http://www.brusselstimes.com/magazine2/12050/the-flemish-movementhow-language-shaped-belgium(Date accessed: 09.01.2018).

80. VANDERSTAPPEN T. The Flemish Movement: How language shaped Belgium. [Electronic resource]. Access mode: http://www.brusselstimes.com/magazine2/12050/the-flemish-movement-how-languageshaped-belgium (Date accessed: 09.11.2018).

81. WALTER, H. Le Français dans tous les sens, Paris, Robert Laffont, 1988.-P.126. 82. Welsh Government. (2011). Review of the Welsh Language Support Service for School. [Electronic resource]. Access mode: http:// www.wales.gov.uk/statistics-andresearch/re(Date accessed: 22.04.2019).

83. WINTER, E. Frühliberalismus in der Donaumonarchie: Religiöse, nationale und wissenschaftliche Strömungen von 1790-1868. Berlin: Akademie Verlag. -1968. -P.23. 84. WITHERS, C.W.J., Gaelic in Scotland 1698-1981. Edinburgh: John Donald Publishers LTD.1984.-P.241. 
IUS ET SCIENTIA (ISSN 244-8478) 2019, Vol. 5, nº 2, pp. 145-189. ANÁLISIS CIENTÍFICO-JURÍDICO COMPARATIVO DE LA POLÍTICA LINGÜÍSTICA EN RELACIÓN CON LAS MINORÍAS NACIONALES. Iliana elyana.valiulina@gmail.com Universidad de los Urales (Rusia) Recibido: 17/09/2019. Aceptado: 10/10/2019 DOI: http://doi.org/10.12795/IESTSCIENTIA.2019.i02.07

85. YEATS W. B. The Bounty of Sweden. [Electronic resource]. Access mode: http://www.nobelprize.org/nobel_prizes/literature/laureates/1923/yeats-lecture.html (date accessed:04.04.2019).

86. YEATS W.B. The Decline of the Irish Language in the Nineteenth Century. [Electronic resource]. Access mode: https://www.yeatssociety.com/news/2015/03/09/the-decline-of-the-irish-language-inthe-nineteenth-century/ (date accessed: 31.03.2019). 